\title{
Las fracturas sociales y la relación estado-sociedad en Bolivia y Venezuela. Fundamentos para una explicación de largo plazo*
}

\author{
Social fractures and the state-society relationship in Bolivia and \\ Venezuela. Foundations for a long-term solution \\ As fraturas sociais e a relação estado-sociedade na Bolívia e na \\ Venezuela. Bases para uma explicação de longo prazo
}

Ricardo Gaytán Cortés**

\begin{abstract}
RESUMEN
A finales de la década de los noventa América Latina experimen-

tó el denominado giro a la izquierda, con la llegada al poder de gobiernos calificados de posneoliberales. Entre ellos las experiencias que en ese momento se visualizaron como las más radicales en su rompimiento con el pasado fueron las de Bolivia y Venezuela. Hoy en ambos países se viven momentos de agitación y crisis. El presente artículo propone explicaciones acerca de los límites estructurales para los cambios que se buscó llevar a cabo. A partir de un análisis de largo plazo, auxiliándonos de la sociología histórica y centrándonos en las fracturas sociales se describe la presencia de las fracturas territorial, étnica y de clase en Bolivia y de clase en Venezuela; y la manera en que se configuró la relación Estado-sociedad, particularmente a través de la inte-
\end{abstract}

Palabras clave: Bolivia, forma estatal, fracturas sociales, sociología histórica, Venezuela.

\footnotetext{
* El presente artículo forma parte de los resultados del trabajo: "Formas y autonomía del Estado. Posibilidades y límites. Bolivia y Venezuela en perspectiva comparativa", tesis inédita presentada para obtener el grado de Doctor en Ciencias Sociales por la Universidad Autónoma del Estado de Hidalgo. Investigación financiada por el Consejo Nacional de Ciencia y Tecnología (CONACYT) y por el Ministerio de Educación de la Nación Argentina. Una primera versión se presentó en las XIII Jornadas de Sociología de la Universidad de Buenos Aires en 2019.

** Mexicano. Doctor en Ciencias Sociales por la Universidad Autónoma del Estado de Hidalgo (UAEH). Profesor por asignatura, Universidad Autónoma del Estado de Hidalgo (UAEH). Pachuca de Soto, México.rgaytan_c@hotmail.com
} 
gración de las coaliciones dominantes y la presencia de centros de poder autónomos. Con ello, se busca argumentar en cuanto a la importancia de las perspectivas de largo plazo y respecto de los resultados a los que conducen.

\begin{abstract}
At the end of the 1990s, Latin America experienced the so-called shift to the left, with so-called post-neoliberal governments coming to power. Amongst the experiences that were seen at the time, Bolivia and Venezuela were the most radical in breaking with the past. Both countries are currently experiencing turmoil and crisis. This article proposes explanations of the structural limits to the changes that were sought. Based on a long-term analysis, using historical sociology and focusing on social fractures, it describes the presence of territorial, ethnic and class fractures in Bolivia and class fractures in Venezuela, and the way in which the state-society relationship was constructed, particularly through the integration of the dominant coalitions and the presence of autonomous centers of power. In doing so, it seeks to argue for the importance of long-term perspectives and the outcomes that they lead to.
\end{abstract}

\section{RESUMO}

No final dos anos 90, a América Latina experimentou a chamada guinada à esquerda, com a chegada ao poder de governos descritos como pós-neoliberais. Entre eles, as experiências que na época foram vistas como as mais radicais em sua ruptura com o passado foram as da Bolívia e da Venezuela. Hoje, ambos os países estão passando por momentos de agitação e crise. Este artigo propõe explicações sobre os limites estruturais para as mudanças que tentaram ser implementadas. A partir de uma análise de longo prazo, com a ajuda da sociologia histórica e o foco nas fraturas sociais, descreve-se a presença de fraturas territoriais, étnicas e de classe na Bolívia e de fraturas de classe na Venezuela; além da forma como a relação Estado-sociedade foi configurada, particularmente através da integração das coalizões dominantes e da presença de centros autônomos de poder. Ao fazer isso, procura-se argumentar sobre a importância das perspectivas de longo prazo e a respeito dos resultados aos quais elas conduzem.
Keywords: Bolivia, state form, social fractures, historical sociology, Venezuela.

Palavras-chave: Bolívia, forma estatal, fraturas sociais, sociologia histórica, Venezuela. 


\section{Introducción}

A finales de la década de los noventa del siglo pasado América Latina experimentó el denominado giro a la izquierda, con la llegada de gobiernos en varios países de la región considerados progresistas o posneoliberales. De estos países, Venezuela y Bolivia fueron identificados como los que tuvieron una mayor ruptura con su pasado inmediato ( $\mathrm{Pe}$ tras, 2013; Sader, 2009; Torrico, 2017). Dos décadas después de iniciado el ciclo, Venezuela está sumergida en una crisis económica, política y social de enormes proporciones (Andreani, 2018; Ávila, 2019; Freitez, 2019; Llorens, 2018; Magdaleno, 2018), mientras que Bolivia, que parecía ser el único país en darle continuidad al proyecto, con avances importantes en materia de inclusión social y crecimiento económico (Molina, 2019a; Programa de las Naciones Unidas para el Desarrollo [PNUD], 2015), se encuentra también en una profunda crisis política.

El objetivo de este artículo es presentar un análisis respecto de las fracturas sociales y la manera en que se configuró la relación Estadosociedad a partir de la segunda mitad del siglo pasado, con el fin de buscar explicaciones que mejoren nuestra comprensión de las situaciones en las que están sumergidas ambos países.

Para ello, realizaremos un análisis histórico estructural, auxiliándonos de la sociología histórica, comparando los casos de Bolivia y Venezuela. En primer lugar, se expondrán las fracturas sociales (en Bolivia se identifican las fracturas territorial, étnica y de clase; mientras que en Venezuela solo se encuentra la fractura de clase). En seguida se argumentará que, para explicar las situaciones en curso son fundamentales la manera en la que se han configurado a largo plazo las relaciones Estado-sociedad a partir de la conformación de las coaliciones dominantes en el poder y la presencia de centros de poder autónomos, aunado a las fracturas sociales.

\section{Consideraciones metodológicas}

Se propone un análisis desde la sociología histórica, corriente que pugna por una reposición de la temporalidad y la historia al interior de la sociología (Ansaldi y Giordano, 2012a), contraponiéndose a interpretaciones estáticas de los fenómenos sociales y que busca explicar los procesos sociales a largo plazo (Juliá, 1989). 
Entre los autores que pueden adscribirse a esta corriente encontramos a Theda Skocpol (1984) — gran defensora del movimiento (Ramos, 1993) - , con su trabajo comparativo de la revoluciones socioeconómicas; Michael Mann $(1991$; 1997) con un ambicioso estudio referido a las fuentes del poder social; y Charles Tilly $(1992 ; 2010)$ en sus análisis acerca e la conformación de los Estados europeos y la democracia. En Latinoamérica, la obra de Waldo Ansaldi y Verónica Giordano (2012a; 2012b) explica la construcción del orden en la región a partir de la independencia mediante esta "hibridación de disciplinas" (Dogan y Pahre, 1993 citado en Ansaldi y Giordano, 2012a, p. 41).

El presente artículo es un estudio que recupera la dimensión histórica del proceso, a la par que profundiza desde la perspectiva estructural en la comparación de los dos países elegidos, mediante una profunda revisión bibliográfica que reconstruye las dimensiones de análisis propuestas.

Al hacer referencia al largo plazo se toma una licencia descriptiva para diferenciarse de los análisis de coyuntura, que tienden a ignorar la dimensión histórica. La manera en que Ansaldi y Giordano (2012b) hablan de la longue durée de Braudel: "una conexión entre el pasado y el presente o, dicho de otro modo, la continuidad o la presencia del pasado en el presente, esto es, cristalizaciones" (p. 683), sintetiza de forma admirable la pretensión del artículo. Se sostiene la necesidad de mirar al pasado y, a partir de ello, reconstruir procesos y relaciones, en coincidencia con otros trabajos que para Bolivia (Pinto, 2005; Uharte, 2013) y Venezuela (Caballero, 1998; Nava, 2007), utilizan la historia para explicar el presente.

Respecto de la temporalidad, con el fin de simplificar la narrativa y la comparación, se hace referencia a las formas estatales (Mann, 1997). En ese sentido, se identifican cuatro formas presentes en ambos países: el Estado oligárquico, el Estado nacionalista desarrollista, el Estado neoliberal y el Estado posneoliberal.

El Estado oligárquico, nombre que hace referencia al tipo de dominación, es con el que Bolivia y Venezuela iniciaron el siglo XX y que duró sus primeras décadas (Ansaldi y Giordano, 2012a). En Bolivia la transformación de la forma estatal derivó de la guerra del Chaco, sostenida contra Paraguay entre 1932 y 1935, cuya derrota llevó a la descom- 
posición de la forma de dominación (Klein, 1993), que culminó en la revolución nacionalista de 1952, barriendo las instituciones oligárquicas (Dunkerley, 2003). Mientras que en Venezuela la forma oligárquica se desarticuló como producto de la lenta transformación propiciada por el petróleo, que se reflejó finalmente en el denominado "trienio adeco" entre 1945 y 1948, cuando llegó al poder, mediante un golpe de Estado, una coalición de mandos medios del ejército y un grupo de clase media agrupado en torno al partido Acción Democrática (AD), el que procedió a liquidar los resto del gomecismo (Caballero, 1985; 1998; Jácome, 1999; López, 1986; Nava, 2007).

Los años de 1945 y 1952, por lo tanto, marcaron el ascenso de una nueva forma: el Estado nacionalista desarrollista, que estaría presente en Bolivia hasta 1985 y en Venezuela hasta 1989. La ampliación de la población políticamente relevante, el estatismo, la industrialización por sustitución de importaciones, las nacionalizaciones y un énfasis redistributivo caracterizaron el periodo.

El fracaso de la gestión de la Unidad Democrática y Popular (UDP) en Bolivia, coalición de las izquierdas partidarias y sindicales que marcó el fin de las dictaduras militares y gobernó el país de 1982 a 1985 (Lazarte y Pacheco, 1992), dio paso a una nueva forma estatal, el Estado neoliberal (oficialmente iniciaría con la publicación del decreto 21.060 en agosto de 1985), que buscaba estabilizar la economía y llevar a cabo una serie de reformas estructurales para abrirla, en sintonía con el pensamiento económico dominante (Barja 1999; Morales, 1993). Mientras que la elección por segunda ocasión de Carlos Andrés Pérez para la presidencia de Venezuela en 1989 y la presentación de "el gran viraje" ante la crisis económica, marcaron el inicio de las reformas estructurales identificadas con el neoliberalismo, que tendrían su desarrollo más exitoso en la denominada "apertura petrolera" (Ellner, 2009; Gil, 1992; Lander, 1997; López, 2005), a pesar de una marcada resistencia por parte de la ciudadanía y de grupos políticos a adoptar esa forma estatal.

En Bolivia la forma neoliberal estuvo vigente hasta inicios de los dos mil, en que se aceleró su descomposición, a partir de la guerra del agua en Cochabamba, los levantamientos aymaras en el altiplano y la guerra del gas en 2003 (Garay y Mendoza, 2015; Kruse, 2005; Rojas, 2015), que terminó con la huida del presidente Gonzalo Sánchez de 
Lozada, en su segundo periodo presidencial y uno de los principales arquitectos de las reformas (Rojas, 2009). En 2005 fue electo Evo Morales como presidente, quien inició una serie de políticas que transformarían la forma estatal. En Venezuela, los intentos de imponer el modelo neoliberal duraron hasta 1998 con la elección de Hugo Chávez para la Presidencia, que postuló una agenda antineoliberal y llevó a cabo sus propuestas de campaña, materializando una parte de ellas en una nueva Constitución.

Las elecciones de Chávez y Morales marcaron el fin de la forma neoliberal, con lo que inició el Estado posneoliberal, cuya identidad todavía se encuentra en disputa en los círculos académicos (Torrico, 2017). Hay un marcado regreso al estatismo, con las nacionalizaciones y una mayor intervención del Estado en la economía, un neodesarrollismo basado en el extractivismo, junto con apelaciones a la democracia protagónica y participativa en la Constitución venezolana y una reivindicación constitucional y discursiva de la pluralidad nacional en Bolivia.

El derrocamiento del gobierno de Morales en 2019 por parte de una coalición -que incluyó mayoritariamente a las clases medias urbanas, encabezadas por representantes de las élites conservadoras aliadas con el ejército y la policía-, y sus intentos de transformar la forma estatal, fue derrotado en las urnas en octubre de 2020, con la elección de Luis Arce como presidente, lo que deja todavía muchas incógnitas acerca del actuar del nuevo mandatario y las medidas de política pública que tomará, así como si las fuerzas opositoras podrán recuperarse pronto del descalabro.

Mientras que la deriva autoritaria y la catástrofe económica venezolana requieren contextualizar las diferentes etapas que ha adoptado el proyecto estatal chavista, tanto en el gobierno de Chávez como el de su sucesor Nicolás Maduro (Ellner, 2014; López, 2016b), la más reciente de esas etapas parece una encubierta liberalización económica, mientras se aprietan los resortes autoritarios del régimen en lo político (García-Guadilla, 2020).

Si bien las formas estatales facilitan la comparación, también debemos hacer constar que hay diferencias importantes. Venezuela cultivó un Estado fuerte, centralizado, poderoso, caracterizado excelentemen- 
te en la idea del "Estado mágico" de Fernando Coronil (2002). Mientras que el Estado boliviano ha sido tradicionalmente débil: presenta agujeros en donde se negocia la autoridad estatal (PNUD, 2007). Lo que a su vez corresponde a una sociedad organizada y combativa, en el caso boliviano, y a una sociedad dinámica en el caso venezolano, pero sin articulación organizativa autónoma, derivada de la centralidad que adquirirían los partidos políticos y el Estado y su capacidad de cooptación producto de la renta petrolera (Bracamonte, 2015; Kornblith, 1998; López, 1981; Rey, 2015), esto es, una sociedad efervescente, pero que no ha tenido la misma incidencia que la sociedad boliviana en su lucha con el Estado.

Por lo tanto, la comparación permite ver no solo las aproximaciones, sino también las diferencias - que en última instancia y de acuerdo con nuestro argumento-, explican los resultados hasta este momento. Para los fines del presente artículo nos concentraremos en las últimas tres formas estatales mencionadas.

Por último, también como consideración metodológica, se usan variables de análisis políticas y endógenas, sin perder de vista factores como la importancia de la situación internacional y de la geopolítica donde la influencia de Estados Unidos en la región es innegable (Cockcroft, 2001; Curzio, 2011); los procesos de globalización y la dependencia de los países periféricos (Robinson, 2015); la influencia de las ideologías externas, a la que somos tan afines en América Latina (Hobsbawm, 2014); y, finalmente, el peso de las variables económicas en el rumbo de los países. El embargo petrolero y económico venezolano, el impacto del informe de la Organización de los Estados Americanos, OEA, sobre las elecciones de 2019 en Bolivia, la disputa por la explotación del litio en el mismo país, son sucesos muy relevantes, pero que no consideraremos como factores explicativos determinantes en los casos de estudio, por lo que en términos generales nos remitimos a la estructura social interna y no a la intervención externa.

\section{Las fracturas sociales}

En primer lugar, analizaremos las principales fracturas sociales presentes en Bolivia y Venezuela, entendiendo estas como el "sistema de contrastes y divisiones de una comunidad nacional" (Lipset y Rokkan, 
2001, p. 231). Argumentamos que en el caso boliviano se encuentran presentes a lo largo de su historia las fracturas territorial, étnica y de clase, mientras que en el caso venezolano se encuentra presente solamente la fractura de clase.

En Bolivia después de su independencia y hasta bien entrado el siglo XX hubo una lucha por definir el centro del Estado, puesto en cuestión por los departamentos (Albó, 2009; Barragán, 2009a; Blanes, 1993; Mesa, 2012; Roca, 2005; 2009). En el siglo XIX, nos recuerda José Luis Roca (2009) la región dominante cambiaba, era una capital "itinerante y nómada" (pp. 77-78). Chuquisaca, que fuera sede de la audiencia de Charcas durante la Colonia, no fue capaz de mantener el poder y como resultado el Legislativo se reunía en cuatro ciudades distintas, Sucre, La Paz, Oruro y Cochabamba, y el ejecutivo en dos, Sucre y La Paz. El conflicto se resolvió en 1899 a favor de La Paz —en lo que se conoce como la guerra federal一, aunque formalmente Sucre siguió conservando la dignidad de capital de la República y sede del Poder Judicial. Con posterioridad hay un realineamiento regional y el enfrentamiento, que adquirió bastante importancia en la década de los dos mil, fue entre La Paz y Santa Cruz, Occidente y Oriente, capital política y motor exportador (Bustos, 2011; Soruco, 2008a).

No hay que olvidar que en los departamentos orientales, Santa Cruz, Beni y Pando, que conforman la denominada "media luna" hay un "predominio de la herencia hispánica y poca influencia indígena" (Roca, 2009, p. 78), aparte de la presencia de una agroindustria importante, paradójicamente impulsada como parte de las metas de la revolución nacionalista de 1952 (Barragán, 2009a; 2009b; Dunkerley, 2003; Ormachea, 1987; PNUD, 2004; Soruco, 2008b).

Los ingresos de los departamentos también reflejan esta fractura, toda vez que ocurre un proceso de diferenciación entre el tesoro central y los tesoros departamentales. Respecto de los ingresos petroleros, se permite que el departamento en que aquellos se extraen se quede con un porcentaje de los impuestos en forma de regalías petroleras, antes de que el resto vaya a parar al Tesoro Central para su distribución y gasto, lo que propicia el fortalecimiento de los lugares donde se encuentran los yacimientos, especialmente en el oriente boliviano. Ocurre lo contrario con la minería, pues sus ingresos son considerados nacionales y automáticamente van a parar casi en su totalidad al 
Tesoro Central, si bien existe la figura de la regalía minera, pero por su forma de cálculo es considerablemente menor, aunque hay intentos para acabar con esa inequidad (Ayala, 2011; Barragán, 2009b; Bustos, 2011; Cardozo, 2018; Mesa, 2012; PNUD, 2004).

Por lo tanto, se encuentra presente una fractura territorial, relacionada con la centralización-descentralización, pero también la identidad nacional está en juego y es objeto de disputa. La discusión acerca de la nación boliviana y la larga memoria étnica de los pueblos originarios con su contraparte el mestizaje y la homogeneización, se reflejó desde la Colonia en lo que se dio en llamar "las dos repúblicas". Lo que Tristan Platt (citado en Albó, 2009) llamó el implícito "pacto colonial" (p. 21), que legitimaba ante la Corona la persistencia de los pueblos indios. Dicho pacto continuó después de la independencia y solo se quebró cuando la minería ofreció de nuevo un ingreso estable al naciente Estado, con lo que el tributo indio ya no era indispensable para el mantenimiento de su aparato (Barragán, 2009a; PNUD, 2007; Rivera, 1993), lo cual condujo a que durante la etapa liberal se ignorara sistemáticamente al indígena (Albó, 2009), aunque no a sus tierras y su organización en comunidades, que fueron objeto de constantes ataques, hasta dar paso a otro enfoque que se materializó en la revolución de 1952, el de crear una nación homogénea e "incluyente", una nación mestiza sin reconocimiento de la diversidad étnico-cultural (Albó, 2009; Barragán, 2005; Gray, 2009; PNUD, 2007; Rivera, 1993; 2010).

Los procesos de homologación derivados de esas acciones fueron exitosos en algunas regiones, como en Cochabamba, cuyas historias particulares impulsaron y facilitaron la visión de la elite estatal, pero generaron también resistencias en otras zonas, o bien, procesos de separación de la órbita estatal ante lo que se percibió como una imposición más (Rivera, 2010; Soto, 1994). Como bien recuerda Silvia Rivera (2010):

Hablar de luchas campesinas en Bolivia supone una necesaria aclaración. El término "campesino" oficialmente adoptado en el país a partir de la revolución de 1952, suele enmascarar los contenidos que desarrollaron en su lucha las poblaciones rurales predominantemente indias (qhechwa, aymara, guaraní, etc.) durante el período republicano. (p. 73). 
La identidad de la nación se encontró en discusión nuevamente con el fracaso del Estado neoliberal y el ascenso de los movimientos sociales que respaldaron la elección de Evo Morales, primer presidente indígena del país, impulsándose una visión plurinacional que hizo énfasis en la diversidad al interior de Bolivia.

Finalmente, hay una tercera fractura presente en la sociedad boliviana: la relacionada con la clase social. La presencia de una oligarquía, entre finales del siglo XIX y principios del siglo XX, que monopolizó la principal exportación del país - plata o estaño-, tuvo su momento culminante en el llamado superestado minero con los barones del estaño, quienes no se involucraron directamente en el control del Estado, pero sí velaron por sus intereses, apoyados por un sector de la clase media, la famosa "rosca" (Klein, 1993; Pérez, 2014). La revolución nacional de 1952 trató de subsanar esa situación: desarticuló a la oligarquía minera, expropió el estaño y lo administró estatalmente mediante la Corporación Minera de Bolivia (COMIBOL) y dio acceso a los excluidos - universalizó el voto, llevó a cabo una importante reforma agraria en 1953, y acabó casi hasta los cimientos con las bases del viejo Estado-; paradójicamente, la forma estatal resultante construyó las bases de una nueva clase económica agroindustrial en el oriente (Dunkerley, 2003; Soruco, 2008b).

El gran conflicto a partir de la década de los cuarenta hasta los ochenta del siglo pasado fue el de clase. Por un lado, los sindicatos obreros con los mineros como punta de lanza; por el otro, se consolidó una coalición liderada por los militares de derecha, en conjunto con la naciente agroindustria oriental y otras capas de la burguesía, apoyados por Estados Unidos en su lucha contra el comunismo (Dunkerley, 2003; Lazarte y Pacheco, 1992). Los campesinos jugaron un papel ambivalente y subordinado: en un primer momento apoyaron el régimen de 1952, luego adoptaron un papel conservador con el gobierno del general René Barrientos y, posteriormente, sufrieron una represión selectiva, articulando lentamente su autonomía en un momento en el que parecían perder importancia y volverse irrelevantes (Dunkerley, 2003; Lazarte y Pacheco, 1992; Rivera, 2010; Soto, 1994).

La posibilidad de trasformar las relaciones de clase pareció desaparecer con el estrepitoso fracaso de la UDP en el período 1982-1985. El trauma y el desprestigio de los actores y el proyecto (Lazarte y Pacheco, 
1992), fue tal que no volverán a mencionarse como opciones reales de transformación social.

Hay una aparente superposición de dicha fractura por la étnica en los últimos lustros, pero no podemos olvidar el origen de Evo Morales como líder del sindicato de cocaleros, quienes buscaban tener representación parlamentaria y municipal (Zuazo, 2009). Es decir, un acceso relacionado con una clase campesina ligada con ciertas reivindicaciones económicas y sociales más que étnicas, exigencia que sufrirá una revaloración a partir de la década de los noventa producto de las luchas de los pueblos originarios (Bengoa, 2007) —bandera de la que se apoderarán con posterioridad-, por lo que la cuestión de clase y la étnica se fusionan en cierta medida (Crabtree, 2009; García, 2010; Zuazo, 2009), e incluso se agrega la fractura territorial (Bonifaz, 2012); lo campesino quedó subsumido a lo indígena (García et al., 2010). Fue cuando el conflicto se volvió territorial y étnico, la reconversión fue lenta, las esperanzas en el nuevo paradigma neoliberal, las concesiones que hizo, y los aparentes resultados dieron quince años de tregua.

Cuando esas fracturas se hicieron presentes los actores se encontraban en pleno proceso de consolidación, con una base territorial y económica diferentes. El enfrentamiento duró casi una década y concluyó, aparentemente, con una tregua y concesiones de ambos lados: las autonomías territoriales y departamentales y el carácter plurinacional del Estado, que parecieron contentar a los protagonistas desactivaron los elementos más radicales de cada discurso, y se retomó la idea de normalidad y estabilidad (Mayorga, 2011; Rojas, 2015). El conflicto recayó en la construcción de la nación, de quiénes son sus miembros, bajo qué condiciones y cómo se distribuye el poder en su territorio.

Estas tres fracturas - territorial, étnica y de clase-, atraviesan a la sociedad boliviana y se reflejan en la forma estatal y la relación Estadosociedad, así como en las crisis, luchas, e instituciones resultantes. La última gran manifestación fue el conflicto entre occidente y oriente y su solución fue la aprobación del texto constitucional de 2009. Hoy nuevamente se encuentran en disputa con el derrocamiento del gobierno de Evo Morales y se pueden ver en: los liderazgos regionales que participaron en el ciclo de protestas, sobre todo Santa Cruz y Potosí; las alianzas en contra del gobierno de Morales, conformadas por sectores urbanos y de clase media; la reivindicación del conservadurismo, pero 
también de una noción liberal de democracia, y la negación de la plurinacionalidad (Molina, 2019b).

En cuanto a Venezuela las fracturas son diferentes, pues solo se encuentra la de clase, que desde la década de los ochenta se configuró soterradamente como el gran eje del conflicto social y se exacerbó con la llegada y su explotación en el discurso de Chávez.

Respecto de la fractura territorial, mientras que en Bolivia el centro mismo del Estado ha estado en cuestión, en Venezuela la región central, configurada por Caracas y sus alrededores, desde muy temprano reafirmó su papel (Nava, 2007).

Resultado de la férrea y prolongada dictadura del general Juan Vicente Gómez (1908-1935) se creó la base de un Estado moderno, al unificar al país territorial y políticamente. La modernización de la hacienda pública y del Ejército, favorecida por los ingresos petroleros, permitió la desaparición de los caudillos regionales y la llegada del Estado a territorios que hasta ese momento habían permanecido fuera de su esfera de influencia (Caballero, 1998; Rey, 1991). La renta petrolera se volvió el principal ingreso estatal y se centralizó a partir de 1922 cuando se eliminaron las concesiones a los terratenientes e intermediarios nacionales privados (Melcher, 1995). A partir de 1930 hubo "un proceso más marcado de fortalecimiento del poder político y económico por parte del gobierno central y un debilitamiento de las autonomías regionales" (Kornblith y Maingon, 1985, p. 46).

Nuevamente los ingresos del Estado son un buen indicador de la centralización. El denominado situado constitucional, establece los ingresos que corresponden a las regiones y, de acuerdo con Miriam Kornblith y Thais Maingon (1985), desde tiempos de Gómez, cuando se suprimieron las rentas de los estados como ramos autónomos, "se constituyó en un instrumento de concentración del poder político y económico en el Gobierno Central por cuanto garantiza la supeditación de las regiones a este" (p. 57). De esa manera, las diversas constituciones que tuvo Venezuela durante la primera parte del siglo XX favorecían la discrecionalidad en el reparto presupuestal, pues una parte importante de los ingresos provenía del petróleo que era administrado centralmente. La explotación de petróleo propició "la enorme concentración geográfica de la población —así como la actividad eco- 
nómica - en torno a la capital y en general a la franja urbana costera aledaña a la zona de producción y exportación de petróleo" (Mieres, 1982, p. 442).

Hay que recalcar la importancia del petróleo en la conformación del Estado y de la sociedad venezolana, no solo en materia de ingresos fiscales, sino como un ente configurador de la nación misma (Coronil, 2002) y creador de una "cultura del petróleo" que permea a toda la sociedad (Quintero, 1972). Su descubrimiento y el surgimiento de la industria petrolera marcaron indefectiblemente la historia reciente del país. Permitió dejar atrás la debilidad decimonónica del Estado, facilitó el financiamiento para los procesos de industrialización y, a su vez, incidió profundamente en la sociedad venezolana a través del uso y la distribución de los ingresos petroleros y la lucha por apropiarse de un trozo de la renta (Bitar y Troncoso, 1982; Garnica, 1988; Gutman, 1982; Kornblith y Maingon, 1985; Melcher, 1995; Pérez, 1999; Rey, 1991; Romero, 2003). También ha marcado y condicionado los ciclos económicos venezolanos, escapando del control interno al depender de los mercados internacionales en cuanto al precio del petróleo y, en última instancia, apresó al país en la llamada maldición de los recursos (Santeliz, 2017; Vera, 2018; Zambrano, 2015).

Respecto de la fractura étnica, tampoco se encuentra presente en la misma dimensión que en Bolivia, si bien ha habido serios intentos de dotar de derechos a la población afrodescendiente e indígena (Mosonyi, 2009), en realidad esta no ha constituido uno de los principales puntos de discusión acerca de la nación venezolana. El relato de unidad nacional tuvo mayor éxito y se consolidó alrededor del petróleo y sus mitos (Coronil, 2002).

Lo anterior nos remite a la fractura de clase, la cual sí se encuentra muy presente en la sociedad venezolana y cuyos choques se pueden ver particularmente en el apoyo y la oposición a Hugo Chávez, en especial en los enfrentamientos de inicios de los dos mil, pero también en los sectores más afectados por la crisis económica estructural que se arrastró desde los ochenta.

Durante la segunda mitad del siglo XX se consideró a Venezuela una anomalía en la región latinoamericana, azotada en esos momentos por la inestabilidad y las dictaduras militares, mientras que el relato 
venezolano hablaba de una democracia pujante, incluyente, de gran crecimiento económico y, por lo tanto, con la ausencia de una fractura de clase presente en otras latitudes (Ellner, 2014). La revisión de esa narrativa permite arrojar una serie de grietas importantes en ella, y fue justo a finales del siglo XX cuando la fractura de clase estalló, impulsada por un discurso de confrontación que encontró un correlato substancial en las condiciones estructurales e institucionales de la sociedad venezolana.

El conflicto de clase recorre a la sociedad venezolana, pero en un primer momento fue contenido y relegado, derivado de la capacidad distributiva producto de la riqueza petrolera. El Estado desarrollistanacionalista, traía implícita la gran promesa distributiva a partir de los ingresos petroleros. Tanto la clase capitalista como la clase trabajadora, se vieron incluidas en esa promesa. No en balde la mejor caracterización del Pacto de Punto Fijo firmado en 1958, que abrió la "modernidad democrática" en Venezuela, fue como un sistema populista de conciliación de élites (Rey, 1991); el término populista se refiere a la integración de las clases populares, trabajadoras, dentro del crecimiento económico mediante grandes alianzas policlasistas e incluyentes.

La crisis económica de la década de los ochenta terminó con esta ilusión. A partir de esos años el poder adquisitivo de las clases populares y medias cayó, el empobrecimiento de la población aumentó a pasos agigantados, junto con el deterioro en los servicios públicos, el trabajo informal creció y la descomposición institucional se aceleró, el desprestigio acosó a los partidos políticos y a la clase política en general, envuelta en severos escándalos de corrupción (Bracamonte, 2015; Gómez, 1995; Kornblith, 1994, 1998; López, 2005; Moreno, 1996; Rey, 2015). No obstante, a la par se consolidó un poderoso segmento de la clase capitalista local, con vínculos en el exterior, a la cual le apretó la camisa de fuerza del Estado, y un grupo de exitosos profesionistas y tecnócratas formados en universidades extranjeras que tendría mucho que ver en la trasformación de la forma estatal (Lander, 1992; Moreno, 1996).

Las reformas estructurales identificadas con el neoliberalismo fueron impulsadas por esos grupos que, con el apoyo de organismos financieros internacionales, pretendieron abrir la economía protegida 
venezolana, les pidieron sacrificios a los ciudadanos - acostumbrados a la narrativa de la riqueza petrolera y a las bajas tasas impositivas-, en pos de un futuro mejor (Ellner, 2009; Gil, 1992; Gómez, 1993; López, 2005). La respuesta fue un sistemático rechazo a esa agenda.

- En las elecciones de 1989, Carlos Andrés Pérez obtuvo su segunda presidencia con un programa de campaña vago y orientado en términos generales a restablecer "la Gran Venezuela" con la que los electores identificaban su primer mandato — que básicamente se había configurado mediante los petrodólares en la década de los setenta-, fue imposible de concretarse debido a las restricciones económicas producto de la crisis económica.

- En las elecciones de 1993, en las que resultó electo, también por segunda ocasión, Rafael Caldera, con un programa claramente antineoliberal que buscó implementar los dos primeros años de gobierno, tuvo que desistir conforme se profundizó la crisis económica, en particular la crisis bancaria de 1994, y abandonarlo por completo a partir de 1996.

- En 1998 con el triunfo de un candidato antisistema (Ellner, 2009; 2014; Nava, 2009; Rey, 2015).

A partir de las elecciones de 1998 el voto se fue polarizando. En un primer momento Chávez tuvo una coalición amplia a sus espaldas, que incluyó no solo a los sectores populares (su sostén en el futuro), sino a sectores de las clases medias disgustados con las élites políticas dominantes por su corrupción e ineficiencia (López, 2016a). No obstante, en las siguientes elecciones las zonas en las que habitan los sectores populares empezaron a votar mayoritariamente por Chávez, mientras que las zonas ricas de las ciudades votaron por el candidato opositor; también las grandes ciudades sufrieron una pérdida de apoyos chavistas, mientras que las ciudades pequeñas y los entornos rurales siguieron siendo fuente de votos para el proyecto gubernamental (López, 2016b). De ahí la importancia de la fractura de clase en las luchas por venir, azuzada por las desigualdades producto de la descomposición del Estado petrolero.

Aunque la fractura no se manifestó de inmediato. El enfrentamiento inició en el año 2001: paro general, golpe de Estado, paro petrolero, revocatorio, solo el agotamiento detuvo a la oposición, que se replegó y decidió boicotear las elecciones (Coronil, 2005; Lander 
y Navarrete, 2009; López y Lander, 2007; Ruiz, 2012; Torres, 2003). Le dejaron la puerta abierta al presidente Chávez para que acelerara su visión y aprovechara la locomotora económica que representaron los precios altos del petróleo. Las propuestas fueron audaces, el socialismo del siglo XXI, el Estado comunal, las nacionalizaciones, la petrodiplomacia, etc. (Ellner, 2014; López, 2016a; 2016b; 2018; Mora et al., 2017).

Los actores se reorganizaron: por un lado el presidente Chávez a partir del golpe de estado de 2002 se dio cuenta de la debilidad de sus bases de apoyo y de que no podía depender solo de una opinión favorable por parte de los sectores populares y de las clases medias que en un inició lo apoyaron, así que se dedicó a profundizar la polarización en la sociedad venezolana (la oposición hizo lo mismo). Particularmente, apoyando a esos sectores populares, creó programas redistributivos con fines clientelares, entre otros las famosas Misiones, favorecido por la bonanza petrolera (Lander y Navarrete, 2009; Mora et al., 2017). Los sectores proneoliberales, los empresarios, los gerentes, los técnicos, las cadenas de comunicaron, los partidos políticos opositores, la clase media, los convencidos de las bondades del sistema se reagruparon también. Su bandera con el paso del tiempo dejó de ser el neoliberalismo y se volvió el antichavismo.

La muerte de Chávez, la caída de los ingresos petroleros y la crisis económica subsecuente, así como la deriva autoritaria de su sucesor Nicolás Maduro, en particular su dependencia cada vez más marcada del ejército y, en general, el agotamiento del modelo (Andreani, 2018; Aveledo, 2019; Ávila, 2019; Oliveros, 2019), han dado nuevos ánimos a quienes se encuentran enfrentados al régimen, apoyados por una comunidad internacional reacia a dejar que continúe en el poder, junto con la merma del sostén popular al gobierno (Montoya, 2019; Rivero, 2019). El enfrentamiento sigue y no se ve una salida clara a una crisis cada vez de mayores proporciones y de un altísimo costo humano.

\section{Las coaliciones dominantes}

En cuanto a los componentes que configuraron las coaliciones dominantes encontramos una serie de actores que establecieron alianzas y enfrentamientos durante cada etapa estatal. 
Después de la revolución nacionalista de 1952 en Bolivia, y durante todo el periodo del Estado nacionalista-desarrollista, hubo varias grandes etapas en la configuración de sus coaliciones caracterizadas por su inestabilidad. La primera fue el llamado cogobierno, entre el Movimiento Nacionalista Revolucionario (MNR) y la Confederación Obrera Boliviana (COB), que finalizó con la imposición de las dictaduras militares iniciadas mediante un golpe de Estado dado por el general René Barrientos en 1964. A partir de esa fecha oscilan gobiernos militares de derecha y otros afines a la izquierda; cuando se agotó la opción militar, resultado de las luchas por la democratización de la sociedad boliviana, en particular los sindicatos, y la presión internacional -_particularmente de los Estados Unidos, preocupado por el respeto de los derechos humanos-, llegó al poder la UDP, como un último intento de rescatar los postulados de la revolución (Albó, 2008; Dunkerley, 2003; Mesa, 1993; Morales, 1993).

Durante esos periodos encontramos una serie de actores bien definidos. Tenemos por una parte al MNR, que agrupaba inicialmente a sectores de la clase media; a los sindicatos, aglutinados alrededor de la $\mathrm{COB}$, con un peso enorme de los mineros; $y$, una vez que se reagruparon después de la revolución de 1952, a las Fuerzas Armadas, que interactuaron con los demás actores, inclinándose a veces en alianza con uno o con otros, lo que muestra las fuerzas en disputa también dentro de esta institución; los campesinos se encontraron presentes en un primer momento con el gobierno del MNR, después como parte de Pacto Militar-Campesino, sosteniendo la dictadura de Barrientos, para finalmente perder relevancia, aparentemente, a partir del gobierno del general Hugo Banzer (Dunkerley, 2003; Laserna, 1986; Mansilla, 1993; Rivera, 1993; 2010; Soto, 1994).

La revolución también generó nuevos jugadores: la agroindustria de oriente, impulsada y apoyada por el Estado, en particular a partir de periodo de Banzer (Dunkerley, 2003; Rodríguez, 2012; Soruco, 2008b), y la minería mediana (Toranzo, 1993), que tendrían un papel relevante en la siguiente etapa estatal.

Respecto de la coalición dominante en Venezuela, a partir del inicio del Estado desarrollista nacionalista, tenemos tres grandes etapas: el trienio adeco, en el que sectores progresistas de la clase media agrupados en el partido $\mathrm{AD}$ se aliaron con mandos medios del ejército y 
buscaron desmantelar los resabios del Estado oligárquico, apoyados por los restos del campesinado, sectores del proletariado y de la pequeña burguesía. Esta etapa marcó la entrada de dos nuevos actores: el ejército y el partido (Caballero, 1998). Ante lo que consideraron la radicalización del proyecto, una nueva alianza, esta vez entre los sectores conservadores de la sociedad venezolana y los mismos sectores modernizadores del ejército, impondrían un régimen militar desarrollista, que desembocó en la dictadura de Pérez Jiménez (Gómez, 1993; López, 1986).

La caída de la dictadura daría paso al Pacto de Punto Fijo en 1958, estableciendo una democracia pactista, un sistema populista de conciliación de élites (Rey, 1991), que implicó una amplia alianza entre las élites dominantes, los partidos políticos de la clase media, en un primer momento $\mathrm{AD}$, Comité de Organización Política Electoral Independiente (COPEI) y la Unión Republicana Democrática (URD), la Iglesia, el ejército, el empresariado y los trabajadores, agrupados corporativamente, y se basó en el establecimiento de un sistema político partidista, que se iría cerrando en torno a $\mathrm{AD}$ y COPEI, que se apoyó en la redistribución de los recursos petroleros. Fue un sistema que excluyó tanto a las manifestaciones de izquierda, en particular al Partido Comunista Venezolano y sus sindicatos simpatizantes, como a las fuerzas de extrema derecha (Caballero, 1985, 1998; Canelón y González, 1998; Gómez, 1993; Rey, 1991; 2015).

Por su parte, la nueva coalición dominante en Bolivia producida por el ascenso del neoliberalismo se configuró ante el fracaso de las élites anteriores (Barrios, 1993; Morales, 1993). Tanto las Fuerzas Armadas como los partidos y organizaciones de izquierda nacionalistas, representados por la UDP y la COB, quedaron desacreditados. Los sindicatos, ante su creciente radicalización y negativa para llegar a cualquier tipo de acuerdo, perdieron el prestigio que les dio el combatir a las dictaduras militares. Mientras que el ejército se replegó volviéndose parte de "un control civil informal" (Quintana citado en Tellería, 2004, p. 5). Por lo tanto, ascendió una nueva élite conservadora, centrada en los partidos políticos tradicionales, los que dieron un giro - en ocasiones incomodo e inexplicable-, hacia un centro político disfrazado de racionalidad técnica, apoyado por lo que podríamos denominar la minería mediana y la agroindustria de oriente, en una práctica de 
"presidencialismo parlamentarizado" (Mayorga, 1993; 1994; Romero, 2012a, 2012b).

La democracia pactista o pactada se sustentó en acuerdos que favorecieron "la democracia representativa y la economía del mercado" (Mayorga, 1994, p. 42). El hecho de que algunos de los principales dirigentes de los partidos en el gobierno -en particular Sánchez de Lozada, presidente en dos ocasiones y arquitecto de las primeras reformas, y también de los principales partidos opositores, aún en una faceta "neopopulista" - fueran empresarios pareció revestir con cierta inevitabilidad esta nueva etapa (Alenda, 2002; Rojas, 2009; Romero, 2003). Los partidos con mayor presencia MNR, Acción Democrática Nacionalista (ADN) y Movimiento de Izquierda Revolucionaria (MIR), centro, centro derecha y centro izquierda respectivamente, obtuvieron el apoyo de los grupos sociales y regiones más aventajadas, mientras que quienes vieron empeorar su situación o creyeron que sus necesidades no fueron atendidas optaron por otras opciones, como Conciencia de Patria (CONDEPA), que tuvo un apoyo masivo en El Alto y el altiplano paceño (Romero, 2002); el consenso orbitaba alrededor de la competencia partidista y electoral y pareció institucionalizarse.

Respecto de la coalición dominante venezolana responsable del proyecto neoliberal, tenemos una reconfiguración alrededor de AD y COPEI y el ascenso de una elite conformada por los grandes empresarios, particularmente de los sectores enfocados al exterior, en conjunto con el capital internacional, organismos financieros internacionales y un grupo de tecnócratas y gerentes convencidos de las bondades del nuevo sistema.

En Venezuela la lucha fue más encarnizada, pues el Estado nacionalista desarrollista no sucumbió en una espectacular crisis de grandes proporciones como en Bolivia, sino que sufrió un paulatino proceso de descomposición, por lo que hay un sector de la élite política, respaldado mayoritariamente por la población, que pudo oponerse legítimamente a las reformas e incluso ganó tres elecciones presidenciales con un discurso antineoliberal o, en el mejor de los casos, ambiguo. Sin embargo, tanto Carlos Andrés Pérez como Rafael Caldera se vieron obligados por las circunstancias - en particular la bajada de los precios del petróleo y la consiguiente crisis de financiamiento estatal-, a llevar a cabo las reformas neoliberales, aún en oposición a sectores de 
sus propios partidos y partidarios (Ellner, 2009; Gómez, 1993; López, 2005; Rey, 2015). El ejército sufrió la misma ambigüedad: el proceso de institucionalización y subordinación al mando civil derivado de Punto Fijo fue interrumpido conforme la situación social se iba deteriorando y en 1992 se sucedieron dos intentos de golpe de Estado, mostrándose las grietas en la institución entre los mandos medios y altos (Jácome, 1999).

En relación con las coaliciones dominantes que respaldaron el ascenso del Estado progresista en Bolivia, tenemos la emergencia y el empoderamiento de nuevos actores territoriales, dentro del sistema político, facilitado a nivel departamental por la Ley de Participación Popular de 1994 (Gray, 2008; Rojas, 2009; Tapia, 2018; Zuazo, 2009; 2012).

Ante la crisis del neoliberalismo estos actores ascendieron al poder, liderados por las organizaciones campesinas y de pueblos originarios, en medio de una gran efervescencia social; incluso sostuvieron entre ellas un pulso para ver qué corriente controlaría el proceso. Finalmente los sindicatos campesinos-indígenas con base territorial en el Chapare lograron imponerse, de la mano uno de sus combativos dirigentes, Evo Morales, en medio de una amplia alianza con otras organizaciones populares y movimientos sociales, respaldados por el voto rural y de los sectores bajos y medios (García et al., 2010; Romero, 2006; Zuazo, 2009; 2012), a través del partido-movimiento Movimiento al Socialismo (MAS), desarticulando el sistema de partidos creado a partir de 1985 (Mayorga, 2004). Lo anterior llevó a un enfrentamiento con una de las bases sociales y territoriales del régimen neoliberal, el Comité Pro Santa Cruz, y la denominada media luna del oriente boliviano (Bustos, 2011; Plata, 2008; Viaña, 2011), en tanto que la oposición fue producto de "la convergencia en las tierras bajas entre prefectos opositores, comités cívicos y grupos empresariales, exigiendo autonomía departamental" (Romero, 2012b, p. 174). La negociación y concertación alrededor de las principales demandas de ambas partes, sobre todo las relacionadas con la autonomía, desarticularon el conflicto, con lo que la nueva coalición dominante boliviana quedaría asentada en el poder.

En el caso de Venezuela se inició el desmantelamiento de la forma neoliberal luego de una alianza entre un sector del ejército, cada 
vez más politizado, conformado por miembros del Movimiento Bolivariano Revolucionario 200, una organización militar clandestina fuertemente ideologizada, y sectores progresistas de la sociedad (López, 2008b), con una base social de clase media y baja y personajes de renombre opuestos a las políticas neoliberales que acompañaron a Chávez en su primer etapa (Torres, 2003).

Conforme el gobierno se radicalizó en sus postulados y sus políticas, sus bases sociales cambiaron, dejaron de lado a la clase media venezolana y a los personajes moderados y fueron remplazados por los sectores populares y una participación cada vez más amplia del ejército, cuyos miembros empezaron a ocupar cargos políticos y administrativos en todos los niveles, lo que se ha vuelto el sostén del régimen (Jácome, 2018; López, 2019a; Petkoff, 2010). En un inicio los oponentes al chavismo se agruparon: la clase alta, la burguesía venezolana, y las clases medias sumadas a sus protestas, con sus órganos partidarios y corporativos. El agotamiento de la oposición en su primer ciclo de protesta y la renuencia de los partidos políticos antichavistas a participar en la vida electoral los condenó a la irrelevancia durante varios años, la par que el gobierno se vio favorecido por los altos ingresos petroleros, lo cual facilitó la consolidación de sus bases sociales mediante vastos programas clientelares. El régimen resultante consolidó las tendencias de largo plazo que ya venían manifestándose en Venezuela: el repudio a los partidos políticos, la concentración del poder en la figura presidencial y la dependencia excesiva del petróleo en la economía venezolana (Gómez, 1995; Rey, 2015).

Por lo tanto, la construcción de coaliciones dominantes adquiere otro carácter en Venezuela. No hay élites territoriales que claramente representen una oposición al centro, derivado del proceso de centralización que describimos anteriormente. Ello se visibiliza en el nivel institucional, donde en los estados no estuvo permitida la elección de los gobernadores hasta 1989, pues anteriormente eran designados por el presidente. Es hasta la década de los ochenta cuando esa situación cambió, en medio de la crisis estatal y económica e intentos de reforma, pero la descentralización no fortaleció a las regiones ni las volvió posibles opositoras a Caracas o a la centralidad del Estado venezolano. Así, los gobernadores pudieron adquirir popularidad en su región y a nivel nacional con base en su buen desempeño y lanzarse a elecciones 
nacionales, pero no con una base territorial, sino dentro del sistema de partidos existente.

Mientras en Bolivia, el derrocamiento de Evo Morales fue resultado de una reconfiguración de fuerzas sociales. Entre los conflictos al interior de la coalición dominante que marcaron su segundo mandato se cuentan: la pérdida de apoyo de las organizaciones indígenas de las tierras bajas derivada del conflicto por la carretera que atraviesa el Territorio Indígena y Parque Nacional Isiboro Sécure (TIPNIS) (Rivera, 2014); la cooptación de los líderes de otras organizaciones sociales, obsequiosos con las decisiones del gobierno a pesar de la renuencia de sus bases (Chuquimia, 2018); los encontronazos con los mineros derivados de las demandas de mejor distribución regional; y finalmente, el intento de Morales por reelegirse una cuarta vez, aun en contra de lo establecido por la Constitución y la voluntad popular, mediante una interpretación a modo del Tribunal Constitucional Plurinacional (Torrez, 2018), aunados a la denuncia del uso faccioso del aparato estatal y la percepción de un creciente autoritarismo (Rojas, 2018; Tapia, 2018).

Las acusaciones de fraude electoral, alentadas por un informe de la OEA sobre presuntas irregularidades en las elecciones, propiciaron un ciclo de protestas, encabezadas por representantes de las clases altas, sectores predominantemente blancos y conservadores, con capacidad de interpelación popular, aliados con algunos sectores indígenas y mineros con base sobre todo en Potosí, apoyados por las ciudades y, en particular, la clase media urbana (Molina, 2019b), en conjunto con la rebelión de la policía. Finalmente la pérdida de apoyo del ejército, cuyo comandante general sugirió la renuncia de Morales, llevó a su salida del poder el 10 de noviembre de 2019 (Stefanoni, 2019; Stefanoni y Molina, 2019).

Como consecuencia de lo anterior, tomó posesión Jeanine Añez como presidenta interina, asociada con los intereses del oriente del país, desarrollando una gestión con un marcado sesgo conservador, signada por actos de represión, así como acusaciones de corrupción e ineficiencia durante el año que duró su mandato (Extremadoiro, 2020; Mayorga, 2020; Moldiz, 2020; Montero, 2020).

Los acontecimientos recientes en Bolivia remiten a las elecciones de octubre de 2020, en las cuales, para sorpresa de las clases medias 
que habían protagonizado las revueltas contra Morales, el MAS ganó en primera vuelta con más del $50 \%$ de votos de la mano de Luis Arce quien, en los primeros meses de gestión y hasta el momento de escribir este artículo, parece llevar a cabo una discreta renovación de liderazgos y pretende hacer ver que el MAS aprendió de sus pasados errores, con un estilo personal más austero y la promesa de no ser candidato a presidente por segunda ocasión (Molina, 2020).

\section{Los centros de poder autónomos}

Los centros de poder autónomos "operan fuera del control de la política pública y fuera de las interacciones regulares ciudadano-Estado", afirma Tilly (2010, p. 111), que además puntualiza que dichos centros son utilizados como una de las dimensiones de los procesos de democratización y desdemocratización, pero consideramos que tienen valor explicativo en cuanto a la relación Estado-sociedad o, incluso, dentro de la lógica de actuación del aparato estatal. Ello no implica que la acción colectiva contenciosa carezca de incidencia, sin embargo, la existencia de formas organizativas con capacidad de articulación y de generar oposición a los designios estatales favorece la capacidad contestataria de esa acción colectiva.

Es precisamente la presencia de estos centros lo que ha originado una importante lucha por el poder político en Bolivia. Diversas organizaciones han escapado o buscado escapar a la lógica estatal, por ejemplo: los sindicatos, las comunidades o los Comités Cívicos. Derivado de las fracturas sociales, varias de estas organizaciones han tenido una base local y pretensiones políticas, por lo que pueden representar un reto serio a los intentos de institucionalizar las relaciones Estadosociedad, fundadas precisamente en el control indisputable sobre el territorio.

Los sindicatos obreros, en particular los mineros, agrupados alrededor de la $\mathrm{COB}$ fueron los principales polos opositores durante la etapa nacionalista desarrollista en el momento de las dictaduras militares de derecha. Es por ello que el régimen llevó a cabo una represión sistemática en su contra (Dunkerley, 2003; Pinto, 2005). Respecto de las comunidades campesinas, en ese momento no representaron un centro alternativo real de poder, pues se plegaron a diferentes intereses, aunque se configuraron poco a poco como actor independiente. Mientras 
que las regiones bolivianas generaron sus propias organizaciones en forma de Comités Cívicos, que tuvieron uno de sus orígenes en Santa Cruz durante las luchas por las regalías petroleras en la década de los cincuenta, precisamente contra las decisiones estatales (Blanes, 1993; Bustos, 2011; Laserna, 1993).

En Venezuela, en tanto, el Estado desarticuló cualquier centro autónomo similar a través de los pactos corporativos y la subordinación del mundo sindical, así como con la irrelevancia del campesinado con una matriz socioeconómica diferente de la boliviana - pues dependió de las haciendas (Carvallo y Ríos, 1985) y no de las comunidades-. El pronto nacimiento de los partidos políticos, previo a organizaciones de masas como sindicatos, fortaleció su presencia y le permitió colonizarlas, por lo que adquirieron fuerza e importancia mayúscula. El petróleo contribuyó a esta centralidad de los partidos, pues su papel de administradores de este recurso y sus posibilidades de cooptación y clientelismo les facilitaron desarticular cualquier alternativa de canalización de intereses. Así mismo, la temprana represión al Partido Comunista Venezolano, la desarticulación de sus sindicatos, la cooptación de organizaciones alternativas, como las asociaciones de vecinos en los setenta y ochenta, la verticalidad del sindicalismo agrupado alrededor de la Confederación de Trabajadores de Venezuela (CTV) y su cercanía a los partidos políticos, son ejemplos de ello (Canelón y González, 1998; Gómez, 1993; 1995; Iturraspe, 1993; Lander, 1995; López, 1981; 2003; Machado, 2009; Rey, 1991; 2015).

Los gobiernos identificados como neoliberales en Bolivia a partir de 1985 buscaron desarticular los polos opositores que actuaban con la lógica descrita. Los sindicatos mineros fueron objeto de un importante desmembramiento mediante la relocalización, que derivó en el despido casi del $\mathbf{8 0 \%}$ de la fuerza de trabajo contratada en la minería estatal entre 1986 y 1990 (Rodríguez, 2001), lo que mermó su capacidad de organización y de oposición a los designios estatales y condenó a la COB a la irrelevancia (García et al., 2010). Para ello, fue necesario todo el poder del Estado, que dictó dos estados de sitio en un año, detuvo a líderes opositores y reprimió manifestaciones obreras (Laserna, 1987; Rojas, 2015). Tal vez ello no hubiera sido posible sin el desprestigio del gobierno de la UDP y de la COB. 
La forma neoliberal en Bolivia se centró en los partidos políticos como las únicas instituciones encargadas de la representación y la canalización de intereses por parte de la sociedad y en el parlamento como la arena para la toma de decisiones (Ibáñez, 1991; Mayorga, 1993; 1994), a semejanza de lo que ya ocurría en Venezuela y en otras tantas democracias representativas. Otras organizaciones, como los Comités Cívicos, no fueron desarticuladas, sino que se vieron como parte de la pluralidad de la sociedad civil boliviana; lo mismo pasó con las asociaciones empresariales (Bustos, 2011; Laserna, 1993; Mayorga, 1993).

En cuanto a los campesinos y pueblos originarios, algunas de sus organizaciones fueron igualmente favorecidas, pero no tenían capacidad real de oposición al Estado, en particular las del oriente del país, aunque conjugaron poderosos símbolos como la "Marcha por el territorio y la dignidad" de 1990; pero aquellos grupos más combativos fueron objeto de represiones sistemáticas, como en el caso de los cocaleros del Chapare (Albó, 2008; García et al., 2010; Guzmán, 2012; Rivera, 2010; 2014).

Los intentos de colocar en el centro a los partidos políticos fracasaron en Bolivia ante la crisis económica y política que se materializó a finales de la década de los noventa, lo que propició una reorganización de los centros de poder autónomos, esta vez en manos de las organizaciones indígenas y campesinas (García, 2010) con la Confederación Sindical Única de Trabajadores Campesinos de Bolivia (CSUTCB) como la principal fuerza de movilización del occidente boliviano (García et al., 2010), y la réplica en las ciudades, en particular El Alto, de las formas organizativas basadas en el sindicado. Esa suma de protestas permitió que la forma neoliberal fuese doblegada.

Respecto de Venezuela, la crisis del sistema resultado del Pacto de Punto Fijo, y del Estado nacionalista desarrollista en términos más generales, sorprendió a la sociedad venezolana, sobre todo a los sectores populares, desorganizados y sin redes de soporte capaces de hacerle frente a las reformas, o bien, integrados corporativamente a los partidos políticos. El mejor ejemplo de ello fue el Caracazo en 1989, ante los incrementos de precios y el descontento que generaron, la reacción adquirió la forma de una revuelta no organizada de saqueos de productos básicos, que fue duramente reprimida por el Estado (Gómez, 1993; López, 2005). 
La movilización social que desde la firma del Pacto de Punto Fijo fue denostada como mecanismo de acción política - pues se dio preferencia a los cauces institucionales a través de los partidos políticos (Rey, 2015)—, se reactivó desde la década de los ochenta, y sobre todo a principios de los noventa. Durante esos años fueron los sectores sociales más desprotegidos los que se movilizaron, los jubilados, los vendedores ambulantes o sectores que tradicionalmente han sido contestatarios en la sociedad venezolana, como los estudiantes. Sin embargo, una vez concluida la presidencia de Pérez tendieron a perder fuerza (Canelón y González, 1998; Gómez, 1995; López, 2002, 2003). Los primeros años de la llegada de Chávez al poder contemplaron la movilización de nuevos sectores, esta vez ligados a la clase media y alta, contra del nuevo presidente, y por el otro lado, la movilización de las clases populares en su defensa (López, 2003).

En Venezuela no podemos hablar de centros de poder autónomos, en particular con base territorial, que fuesen capaces de retar al Estado. Aunque existen diferentes organizaciones, estas actúan como grupos de interés acotados, más que con una lógica autónoma o de confrontación contra el Estado. En el caso de la CTV se desenvolvía dentro de los márgenes institucionales y relacionados únicamente con sus atributos, la relación capital-trabajo y la defensa de sus agremiados ante la pérdida de poder adquisitivo. Otras organizaciones como las asociaciones de vecinos que tuvieron su esplendor en la década de los ochenta (Lander, 1995) no representaban fuentes alternativas de legitimidad o poder importantes. Es por ello que la opción de cambio en los noventa no vino de la sociedad civil, desarticulada, oficialista, deslegitimada o débil, sino de una institución estatal: el ejército, y en particular de un pequeño grupo altamente ideologizado de militares descontentos con el papel represivo otorgado a la institución a partir del Caracazo y con la crisis económica y política que vivía el país (López, 2008a). Hay que recalcar que el ejército venezolano en su conjunto se comportó de forma institucional durante los dos intentos de golpe de Estado en 1992.

Por lo tanto, en el caso boliviano los centros autónomos se volvieron sumamente importantes como factores reales de poder que impulsaron el movimiento que llevó al poder a Morales. Pero también adquirieron la forma de oposición: los Comités Cívicos de la media luna se volvieron la punta de lanza del descontento con el nuevo gobierno 
y protagonizaron un pulso muy importante con él. Los partidos políticos tradicionales de la etapa anterior se vieron rebasados rápidamente y la verdadera lucha se dio entre organizaciones civiles por parte de ambos bandos (Bustos, 2011). Al final, la concertación con los centros de poder autónomos permitió la estabilidad del nuevo gobierno y la consolidación de la nueva forma estatal.

En Venezuela la llegada del nuevo presidente fue resistida también por factores reales de poder que, sin embargo, no constituían centros de poder autónomos reales. Este es el caso del empresariado: si bien, algunos de sus líderes encabezaron las protestas - incluso el presidente en ese entonces de FEDECÁMARAS asumió la Presidencia provisional tras el golpe de Estado de 2002-, su capacidad de convocatoria se mostró limitada, aunque la retención, retirada o minimización de inversiones y su presencia a nivel internacional denunciando la deriva autoritaria del gobierno fueron la manera en que pudieron presentar oposición. Pasó lo mismo con la jerarquía de la iglesia católica, el sindicalismo oficialista e incluso los sectores conservadores de las Fuerzas Armadas, todos actores del golpe (Vilera, 2003). El único centro de poder autónomo que se presentó en el sentido que le damos al término fue el de la alta gerencia de PDVSA, una burocracia que resistió las nuevas políticas relacionadas con el principal producto de exportación del país, que iban en contra de la denominada "Apertura Petrolera" que soterradamente otorgaba el control del petróleo a la iniciativa privada (Lander, 1997) y que, de la misma manera que los sindicatos mineros en Bolivia en los primeros años del neoliberalismo, tuvo que ser desarticulada como actor político como consecuencia del paro petrolero, mediante el despido de sus miembros recalcitrantes (Lander, 2004). La resistencia de la clase alta y media no se articuló propiamente alrededor de las organizaciones existentes, o bien, las organizaciones existentes demostraron ser altamente ineficaces en su capacidad de convocatoria y de aglutinar a la sociedad, por ejemplo la CTV, que no se recuperó de su fracaso de la ola de protestas de 2002-2003, mientras que los sindicatos trataron de ser cooptados mediante la creación de Centrales cercanas al gobierno (Iranzo, 2018).

Los acontecimientos más recientes en ambos casos refuerzan el argumento. El pulso de 2017 llevado a cabo entre manifestantes y el régimen venezolano, cada vez más represivo y autoritario, se saldó con 
la derrota de la intensa movilización popular al no conseguir sus objetivos (Llorens, 2018), y es que la oposición venezolana durante la mayor parte del periodo estudiado se ha formado dentro de los partidos políticos o, en última instancia, en el ejército. A su vez, el chavismo ha reclamado la representación social y corporativa de los sectores venezolanos y ha presionado para desarticular posibles opositores, sindicales o sociales. Respecto de las pretensiones de Juan Guaidó, autodenominado presidente encargado de Venezuela y reconocido como tal por una parte de la comunidad internacional (Rodríguez, 2019), se sustentan en su carácter de presidente de la Asamblea Nacional y en su interpretación de la ruptura de la legalidad (Infante, 2019), aún con sus antecedentes en el movimiento estudiantil y que no es oriundo de Caracas - proviene del estado Vargas- (López, 2019b), su liderazgo nació al interior de lo que queda del sistema de partidos opositores al ocupar formalmente un cargo, es decir, a pesar de su pasado y activismo, Guaidó no nació como un líder social o regional. Lo mismo pasa con los distintos políticos opositores que han ido surgiendo, cuya su implantación social y regional es limitada y no han podido romper el monopolito estatal.

Bolivia presenta una situación muy diferente. Los principales liderazgos que participaron en el ciclo de protestas que terminó con la salida de Morales en el 2019 provinieron de las regiones, no de los partidos, y particularmente de dirigentes de los Comités Cívicos de Santa Cruz y de Potosí, que llevaron a cabo una alianza temporal con el objetivo de sacar a Morales del gobierno, espoleando las protestas de sectores de la clase media y de las ciudades, dejando de lado al candidato que quedó en segundo lugar en las elecciones, Carlos Mesa, auspiciados por la inactividad de la política y del ejército (Molina, 2019b; Stefanoni y Molina, 2019).

\section{A manera de conclusión}

La conjunción de fracturas sociales y la forma en que se ha articulado la relación Estado-sociedad nos permite establecer ciertas interpretaciones en cuanto a procesos y tendencias que en muchas ocasiones escapan al control de los actores.

La persistencia de las fracturas territorial y étnica hacen de Bolivia un caso especial en América Latina, contribuyendo a la debilidad cró- 
nica del Estado y a la lucha por definir la nación. Recordemos que los Estados nación contemporáneos han sido pensados en clave de control territorial y de homologación nacional; a su vez la fortaleza social viene de esas fracturas, de la lucha por evitar la imposición del centro y por no perder las identidades locales. En Venezuela, en tanto, el excedente petrolero refleja la otra cara de la moneda: la centralización y el fortalecimiento del Estado, que se da el lujo de reordenar la sociedad, volviéndola sumamente dependiente con el establecimiento de canales casi exclusivos de interacción en forma de partidos políticos, acotando cualquier autonomía regional, mientras que la identificación de la nación con el Estado petrolero evita reivindicaciones étnicas o locales.

La fractura de clase tuvo otro tratamiento. Mientras que en Bolivia se manifestó en toda su crudeza durante la forma nacionalista desarrollista, en Venezuela fue hasta los estertores de esa forma estatal y un discurso que la capitalizó, que se problematizó de forma política, lo que también nos deja ver que es la fractura más difícil de solucionar.

La relación Estado-sociedad se inscribe en esas coordenadas: en Bolivia las coaliciones dominantes cambian y los actores se reordenan, mientras que en Venezuela pareciera que no hay transformaciones más allá de las siglas: los partidos políticos y el ejército siguen en el centro del escenario, como en los años cuarenta. El resto de actores sociales venezolanos, organizados o no, parecieran ser solo comparsas en la lucha por ocupar el poder estatal. Hasta el momento la Iglesia, los empresarios, las organizaciones populares, los sindicatos, y en general la sociedad, no han podido articular una respuesta alternativa.

La comparación es valiosa y, en conjunto con el análisis histórico, permite arrojar interpretaciones acerca de las situaciones actuales. El reciente derrocamiento de Evo Morales en Bolivia es la caída, una vez más, de una coalición dominante que se sintió firme en el poder, que supuso que controlaba los resortes de un Estado débil y que había dominado finalmente a una sociedad siempre rebelde y contestataria. Las dificultades para deponer a Nicolás Maduro en Venezuela, conformar un núcleo opositor social fuerte e ir en contra de un Estado todavía muy poderoso - más cuando no tiene ya trabas institucionales en su relación con la sociedad-, responden también a una lógica que se configuró a lo largo de la segunda mitad del siglo XX. 


\section{Referencias}

Albó, X. (2008). 25 años de democracia, participación campesino-indígena y cambios reales en la sociedad. En Vicepresidencia de la República (Ed.), Bolivia 25 años construyendo democracia. Visiones sobre el proceso democrático en Bolivia 1982-2007 (pp. 39-58). Vicepresidencia de la República.

Albó, X. (2009). Larga memoria de lo étnico en Bolivia, con temporales oscilaciones. En J. Crabtree, G. Gray Molina, y L. Whitehead (Eds.), Tensiones irresueltas. Bolivia, pasado y presente (pp. 19-40). Programa de las Naciones Unidas para el Desarrollo/ Plural editores.

Alenda, S. (2002). CONDEPA y UCS, ifin del populismo? En Fundemos (Ed.), Opiniones y análisis. Elecciones presidenciales 2002 (pp. 85-122). Fundemos.

Andreani, F. (2018). Las vías enmarañadas del autoritarismo bolivariano. Nueva Sociedad, (274), 44-58.

Ansaldi, W. y Giordano, V. (2012a). La construcción del orden: de la colonia a la disolución de la dominación oligárquica. Ariel.

Ansaldi, W. y Giordano, V. (2012b). La construcción del orden: de las sociedades de masas a las sociedades en procesos de restructuración. Ariel.

Aveledo, R. (2019). Sobre la tarea de los partidos en la superación de la crisis venezolana. En M. Barrios y M. Bisbal (Eds.), Búsqueda de alternativas políticas a la crisis de Venezuela. Seminario Internacional (pp. 53-75). Universidad Católica Andrés Bello.

Ávila, K. (2019). Uso de la fuerza pública y derecho a la vida en Venezuela. Provea.

Ayala, R. (2011). La construcción del nuevo paisaje político tarijeño. Nuevos actores y nuevos mecanismos de decisión política en el departamento. En R. Cortéz (Coord.), Cuadernos de Futuro 26. Claves de la transición del poder (pp. 153-192). Programa de las Naciones Unidas para el Desarrollo, PNUD.

Barja, G. (1999). Las reformas estructurales bolivianas y su impacto sobre las inversiones. Comisión Económica para América Latina y el Caribe, CEPAL.

Barragán, R. (2005). Ciudadanía y elecciones, convenciones y debates. En R. Barragán y J. Roca (Eds.), Cuaderno del Futuro 21. Regiones y poder constituyente en Bolivia. Una historia de pac- 
tos y disputas (pp. 275-458). Programa de las Naciones Unidas para el Desarrollo, PNUD.

Barragán, R. (2009a). De hegemonías y Ejemonías: una perspectiva histórica sobre los recursos del Estado. En J. Crabtree, G. Gray Molina, y L. Whitehead (Eds.), Tensiones irresueltas. Bolivia, pasado y presente (pp. 91-122). Programa de las Naciones Unidas para el Desarrollo, PNUD/Plural editores.

Barragán, R. (2009b). Hegemonías y "Ejemonías": las relaciones entre el Estado Central y las Regiones (Bolivia, 1825-1952). Iconos. Revista de Ciencias Sociales, (34), 39-51. https://www.redalyc.org/articulo.oa?id=509/50911338004

Barrios, R. (1993). Militares, neoliberalismo y democracia. Crisis de la institución armada en Bolivia. En M. Miranda (Comp.), Bolivia en la hora de su modernización (pp. 351-379). Universidad Nacional Autónoma de México, UNAM.

Bengoa, J. (2007). La emergencia indígena en América Latina. Fondo de Cultura Económica.

Bitar, S. y Troncoso, E. (1982). Venezuela: hacia una nueva estrategia industrial. Nueva Sociedad, (62), 113-125. https://nuso.org/ articulo/venezuela-hacia-una-nueva-estrategia-industrial/

Blanes, J. (1993). Descentralización político-administrativa y heterogeneidad regional. En M. Miranda (Comp.), Bolivia en la hora de su modernización (pp. 81-108). Universidad Nacional Autónoma de México, UNAM.

Bonifaz, G. (2012). La emergencia de las autonomías departamentales en el contexto de la brecha entre legalidad y legitimidad. En M. Zuazo, J. Faguet, y G. Bonifaz (Eds.), Descentralización y democratización en Bolivia. La historia del Estado débil, la sociedad rebelde y el anhelo de democracia (pp. 343-418). Friedrich Ebert Stiffung, FES.

Bracamonte, L. (2015). El declive de la democracia liberal de partidos en Venezuela (1974-2001). Fundación Centro de Estudios Latinoamericanos Rómulo Gallegos.

Bustos, M. (2011). La pirámide social y la nueva geometría en la mediación política - Santa Cruz. En R. Cortéz (Coord.), Cuadernos de Futuro 26 (pp. 95-151). https://nuso.org/articulo/venezuela-hacia-una-nueva-estrategia-industrial/PNUD.

Caballero, M. (1985). Betancourt. Populismo y petróleo en Venezuela. Centro Editor de América Latina. 
Caballero, M. (1998). Las crisis de la Venezuela contemporánea. Monte Ávila editores.

Canelón, F. y González, F. (1998). El modelo político puntofijista, desarrollo, agotamiento y perspectiva. Revista Venezolana de Análisis de Coyuntura, 4(1), 11-42.

Cardozo, A. (1 de junio de 2018). ¿Regalías para quién? Agencia de Noticias Fides. https://www.noticiasfides.com/opinion/carlosarmando-cardozo/regalias-para-quien

Carvallo, G. y Ríos, J. (1985). Economía cafetalera y clase dominante en Venezuela, 1830-1920. En E. Florescano (Coord.), Orígenes y desarrollo de la burguesía en América Latina 1700-1955 (pp. 207-248). Nueva Imagen.

Chuquimia, R. (2018). Estado democracia y plurinacionalidad: elementos para el debate. Umbrales. Revista del Postgrado en Ciencias del Desarrollo, (34), 161-186. http://www.cides.edu. bo/webcides2/index.php/component/jdownloads/send/8revista-umbr\%20ales/158-revista-umbrales-34

Coronil, F. (2002). El Estado mágico. Naturaleza, dinero y modernidad en Venezuela. Nueva Sociedad.

Coronil, F. (2005). Estado y nación durante el golpe contra Hugo Chávez. Anuario de Estudios Americanos, 62(1), 87-112. http://estudiosamericanos.revistas.csic.es/index.php/estudiosamericanos/article/view/69/71

Crabtree, J. (2009). Introducción. En J. Crabtree, G. Gray Molina, y L. Whitehead (Eds.), Tensiones irresueltas. Bolivia, pasado y presente (pp. 9-18). Programa de las Naciones Unidas para el Desarrollo, PNUD/Plural editores.

Cockcroft, J. (2001). América Latina y Estados Unidos. Historia y politica país por país. Siglo XXI editores.

Curzio, L. (2011). América Latina vista desde Washington (1959-2009). En J. del Alcázar (Ed.), Historia actual de América Latina 1959-2009 (pp. 21-48). Editorial Tirant lo Blanch.

Dunkerley, J. (2003). Rebelión en las venas. La lucha politica en Bolivia 1952-1982. Plural editores.

Ellner, S. (2009). Las reformas neoliberales y la crisis política venezolana, 1989-1999: antecedentes de llegada de Hugo Chávez al poder. En P. Ayala y P. Quintero (Comps.), Diez años de revolución en Venezuela. Historia, balance y perspectivas (19992009) (pp. 21-44). Editorial Maipue. 
Ellner, S. (2014). El fenómeno Chávez: sus orígenes y su impacto (hasta 2013). Fundación Centro de Estudios Latinoamericanos Rómulo Gallegos (Celarg).

Extremadoiro, R. (2020). Bolivia: apuntes para comprender la caída del MAS más allá dela polarización. Reflexión política, (45),30-43. https://dialnet.unirioja.es/servlet/articulo?codigo $=7556565$

Freitez, A. (2019). Indicadores de la situación social actual en Venezuela. En M. Barrios y M. Bisbal (Eds.), Búsqueda de alternativas políticas a la crisis de Venezuela (pp. 11-24). Universidad Católica Andrés Bello.

Garay, C. y Mendoza, J. (2015). El choque de dos imaginarios geopolíticos en Bolivia. La "Guerra del Gas". Si somos americanos. Revista de Estudios Transfronterizos, 15 (1), 115-139. https:// scielo.conicyt.cl/pdf/ssa/v15nl/art05.pdf

García, Á. (2010). Introducción. En A. García, M. Chávez, y P. Costas (Coords.), Sociología de los movimientos sociales en Bolivia. Estructuras de movilización, repertorios culturales y acción política (pp. 9-26). Plural editores/ Agroecología Universidad Cochabamba/ National Centre of Competence in Research-Norte Sur.

García, Á., Chávez, M. y Costas, P. (Coords.) (2010). Sociología de los movimientos sociales en Bolivia. Estructuras de movilización, repertorios culturales y acción política. Plural editores/ Agroecología Universidad Cochabamba/ National Centre of Competence in Research-Norte Sur.

García-Guadilla, M. (2020). Venezuela 2020: autoritarismo político y pragmatismo económico. Nueva Sociedad, (287), 108-120. https://www.nuso.org/articulo/venezuela-2020-autoritarismo-politico-y-pragmatismo-economico/

Garnica, E. (1988). El petróleo en Venezuela. Revista Economía, (3), 21-41.

Gil, J. (1992). De 1976 a nuestros días. En Fundación John Boulton (Ed)., Política y Economía en Venezuela. 1810-1991 (pp. 293-379). Fundación John Boulton.

Gómez, L. (1993). La socialdemocracia venezolana: del populismo al pragmatismo. En M. Vellinga (Coord.), Democracia y política en América Latina (pp. 264-292). Siglo XXI editores.

Gómez, L. (1995). Crisis de legitimidad e inestabilidad política en Venezuela. Revista Venezolana de Economía y Ciencias Sociales, (2-3), 103-164. 
Gray, G. (2008). Democracia y economía en Bolivia: 25 años de rezago. En Vicepresidencia de la República (Ed.), Bolivia 25 años construyendo democracia. Visiones sobre el proceso democrático en Bolivia 1982-2007 (pp. 77-86). Vicepresidencia de la República.

Gray, G. (2009). Relaciones estado/sociedad en Bolivia: la fuerza de la debilidad. En J. Crabtree, G. Gray Molina, y L. Whitehead (Eds.), Tensiones irresueltas. Bolivia, pasado y presente (pp123-142). Programa de las Naciones Unidas para el Desarrollo, PNUD/Plural editores.

Gutman, G. (1982). Estrategia transnacional en la agroindustria: estudio sobre Venezuela. En G. Gutman y D. Mezger (Eds.), ¿ Nueva o vieja división internacional del trabajo? Industrialización en Venezuela y México. (pp. 181-241). Instituto Latinoamericano de Investigaciones Sociales, ILDIS/ Centro de Estudios del Desarrollo, CENDES/ Editorial Ateneo de Caracas.

Guzmán, G. (2012). La Marcha. (Protesta social y libertad de expresión en América Latina). Editorial Gente Común.

Hobsbawm, E. (2014). Historia del siglo XX. Paidós.

Ibáñez, E. (1991). Movimientos sociales y democracia. Notas sobre la crisis del sindicalismo boliviano. América Latina Hoy, (1). http://dx.doi.org/10.14201/alh.2072

Infante, A. (2019). “Usurpación", más que una noción política, una interpretación desde los sectores populares. En M. Barrios y M. Bisbal (Eds.), Búsqueda de alternativas políticas a la crisis de Venezuela. Seminario Internacional (pp. 35-40). Universidad Católica Andrés Bello.

Iranzo, C. (2018). La triste historia del sindicalismo venezolano en tiempos de revolución. Una aproximación sintética. Nueva Sociedad, (274), 107-118.

Iturraspe, F. (1993). Sindicatos y crisis política y social en Venezuela. Politeia, (16), 269-281. http://biblioteca.clacso.edu.ar/clacso/gt/20101108014636/7iturraspe.pdf

Jácome, F. (1999). Las relaciones cívico-militares en Venezuela (19921997). En R. Diamint, (Ed.), Control civil y fuerzas armadas en las nuevas democracias (pp. 401-432). Universidad Torcuato di Telia, Nuevohacer, Grupo Editor Latinoamericano.

Jácome, F. (2018). Los militares en la política y la economía venezolana. Nueva Sociedad, (274), 119-128. https://nuso.org/articulo/ los-militares-en-la-politica-y-la-economia-de-venezuela/ 
Juliá, S. (1989). Historia social/ Sociología histórica. Siglo XXI editores.

Klein, H. (1993). Orígenes de la Revolución Nacional Boliviana. La crisis de la generación del Chaco. Grijalbo.

Kornblith, M. (1994). La crisis del sistema político venezolano. Nueva Sociedad, (134), 142-157. https://nuso.org/articulo/la-crisis-del-sistema-politico-venezolano/

Kornblith, M. (1998). Representación, partidos políticos y reforma electoral en Venezuela. En T. Manz y M. Zuazo (Coords.), Partidos políticos y representación en América Latina. Nueva Sociedad, Instituto Latinoamericano de Investigaciones Sociales Instituto Latinoamericano de Investigaciones Sociales, ILDIS/Friedrich Ebert Stiffung, FES.

Kornblith, M. y Maingon, T. (1985). Estado y gasto público en Venezuela. 1936-1980. Universidad Central de Venezuela, Ediciones de la Biblioteca.

Kruse, T. (2005). La "Guerra del agua" en Cochabamba, Bolivia: terrenos complejos, convergencias nuevas. En E. de la Garza (Comp.), Sindicatos y nuevos movimientos sociales en América Latina (pp. 121-161). Consejo Latinoamericano de Ciencias Sociales, CLACSO.

Lander, E. (1992). Los aprendices de brujo. Retos tecnocráticos a la política venezolana. Nueva Sociedad, (121), 124-133. https:// nuso.org/articulo/los-aprendices-de-brujo-retos-tecnocratricos-a-la-politica-venezolana/

Lander, E. (1995). Movimientos sociales urbanos, sociedad civil y nuevas formas de ciudadanía en Venezuela. Revista Venezolana de Economía y Ciencias Sociales, (2-3), 165-187.

Lander, E. (17 de abril de 1997). Apertura petrolera en Venezuela: de la nacionalización a la privatización. XX Congreso Internacional de LASA. Guadalajara, México.

Lander, E. (2004). La insurrección de los gerentes: PDVS y el Gobierno de Chávez. Revista Venezolana de Economía y Ciencias Sociales, 10(2), 12-32. https://www.redalyc.org/pdf/177/Resumenes/Resumen_17710202_1.pdf

Lander, E. y Navarrete, P. (2009). La política económica de la izquierda latinoamericana en el Gobierno: el caso de la República Bolivariana de Venezuela. En P. Ayala y P. Quintero (Comps.), Diez años de revolución en Venezuela. Historia, balance y perspectivas (1999-2009). Editorial Maipue. 
Laserna, R. (1986). La acción social en la coyuntura democrática. En F. Calderón (Comp.), Los movimientos sociales ante la crisis (pp. 103-156). Universidad Nacional de Ucayali, UNU/Consejo Latinoamericano de Ciencias Sociales, CLACSO/Instituto de Investigaciones Sociales de la Universidad Nacional Autónoma de México, IISUNAM.

Laserna, R. (1987). Democracias emergentes en Bolivia. En F. Calderón y M. dos Santos, (Eds.), Los conflictos por la constitución de un nuevo orden (pp. 123-147). Consejo Latinoamericano de Ciencias Sociales, CLACSO.

Laserna, R. (1993). Movimientos regionales y descentralización en Bolivia. Una experiencia de concertación. En M. Miranda (Comp.), Bolivia en la hora de su modernización (pp. 109128). Universidad Nacional Autónoma de México, UNAM.

Lazarte, J. y Pacheco, M. (1992). Bolivia: economía y sociedad 1982-1985. Centro de Estudios para el Desarrollo Laboral y Agrario, CEDLA.

Lipset, S. y Rokkan, S. (2001). Estructuras de división, sistemas de partidos y alineamientos electorales. En A. Batlle (Comp.), Diez textos básicos de Ciencia Política (pp. 231-273). Ariel.

Llorens, M. (2018). Dolor país, versión Venezuela. Las protestas de 2017 y sus secuelas. Nueva Sociedad, (274), 71-82. https:// nuso.org/articulo/dolor-pais-version-venezuela/

López, F. (1986). El perezjimenismo: génesis de las dictaduras desarrollistas. Universidad Nacional Autónoma de México, UNAM.

López, M. (1981). El estado venezolano y el movimiento sindical (19581980). Revista sobre Relaciones Industriales y Laborales, (89), 77-90.

López, M. (2002). Protesta y cultura en Venezuela: los marcos de acción colectiva en 1999. Consejo Latinoamericano de Ciencias Sociales, CLACSO.

López, M. (2003). Precariedad institucional, crisis de legitimidad y movilización. En A. Romero, E. Sandoval, y R. Salazar (Coords.), Venezuela: horizonte democrático en el siglo XXI (pp. 14-30). Sociedad Zuliana de Sociología.

López, M. (2005). Del viernes negro al referendo revocatorio. Alfadil Ediciones.

López, M. (2008a). Venezuela: Hugo Chávez y el bolivarianismo. Revista Venezolana de Economía y Ciencias Sociales, 14(3), 55-82. https://www.redalyc.org/pdf/177/17721699005.pdf 
López, M. (2008b). Venezuela ascenso y gobierno de Hugo Chávez y sus fuerzas bolivarianas. Controversia, (190), 11-53. https://revistacontroversia.com/index.php?journal=contr oversia\&page $=$ article \&op=view $\&$ path $\% 5 \mathrm{~B} \% 5 \mathrm{D}=142 \&$ path $\% 5 \mathrm{~B} \% 5 \mathrm{D}=141$

López, M. (2016a). La crisis del chavismo en la Venezuela actual. Estudios Latinoamericanos, (38), 159-185. http://dx.doi. org/10.22201/cela.24484946e.2016.38.57462

López, M. (2016b). El ocaso del chavismo. Venezuela (2005-2015). Editorial Alfa.

López, M. (2018). Socialismo y comunas en Venezuela. Nueva Sociedad, (274), 59-70.

López, M. (2019a). Notas sobre la fuerza armada bolivariana en el proceso de Transición. En M. Barrios y M. Bisbal (Eds.), Búsqueda de alternativas políticas a la crisis de Venezuela. Seminario Internacional (pp. 87-92). Universidad Católica Andrés Bello.

López, M. (18 de febrero de 2019b). Juan Guaidó y la emergencia de un relevo político para Venezuela. Prodavinci. https://prodavinci.com/juan-guaido-y-la-emergencia-de-un-relevopolitico-para-venezuela/

López, M. y Lander, E. (2007). Venezuela: las elecciones presidenciales de 2006 ¿Hacia el socialismo del siglo XXI? Cuadernos del CENDES, 24(64), 1-21. https://www.redalyc.org/ pdf/403/40306401.pdf

Machado, J. (2009). Participación social y consejos comunales en Venezuela. Revista Venezolana de Economía y Ciencias Sociales, 15(1), 173-186. https://www.redalyc.org/ pdf/177/17721678009.pdf

Magdaleno, J. (2018). Escenarios de la encrucijada venezolana. Nueva Sociedad, (274), 152-164. https://static.nuso.org/media/articles/downloads/11.TC_Magdaleno_274.pdf

Mann, M. (1991). Las fuentes del poder social. Tomo I. Alianza Editorial. Mann, M. (1997). Las fuentes del poder social. Tomo II. Alianza Editorial. Mansilla, H. C. F. (1993). Elite del poder, problemas de gobernabilidad y cultura política en Bolivia. En M. Miranda (Comp.), Bolivia en la hora de su modernización (pp. 417-438). Universidad Nacional Autónoma de México, UNAM. 
Mayorga, F. (2011). El poder político de las representaciones sociales. En R. Cortéz (Coord.), Cuadernos de Futuro 26. Claves de la transición del poder (pp.193-248). Programa de las Naciones Unidas para el Desarrollo, PNUD.

Mayorga, F. (2020). Derrota política del MAS y proyecto de restauración oligárquico-señorial. En F. Mayorga (Coord.), Crisis y cambio político en Bolivia. Octubre y noviembre de 2019: la democracia en una encrucijada. (pp. 1-27). Centro de Estudios Superiores Universitarios de la Universidad Mayor de San Simón (CESU-UMSS)/ Comité de Oxford de Ayuda contra el Hambre (Oxford Committee for Famine Relief), Oxfam.

Mayorga, R. (1993). Gobernabilidad, la nueva problemática de la democracia. En M. Miranda (Comp.), Bolivia en la hora de su modernización (pp. 329-349). Universidad Nacional Autónoma de México, UNAM.

Mayorga, R. (1994). Gobernabilidad y reforma política. La experiencia de Bolivia. América Latina Hoy, (8), 35-60. http://dx.doi. org/10.14201/alh.2296

Mayorga, R. (2004). La crisis del sistema de partidos políticos en Bolivia: causas y consecuencias. Cuadernos del CENDES, 21(57), 83-114. https://www.redalyc.org/pdf/403/40305704.pdf

Melcher, D. (1995). La industrialización de Venezuela. Revista Economía, (10), 57-90.

Mesa, C. (1993). Una visión política de Bolivia en el siglo veinte. En M. Miranda (Comp.), Bolivia en la hora de su modernización (pp. 311-327). Universidad Nacional Autónoma de México, UNAM.

Mesa, C. (2012). Bolivia: autonomías y pluralismo político. Un modelo condicionado por el horizonte indígena. En M. Zuazo, J. Faguet, y G. Bonifaz (Eds.), Descentralización y democratización en Bolivia. La historia del Estado débil, la sociedad rebelde y el anhelo de democracia (pp. 43-85). Friedrich Ebert Stiffung, FES.

Mieres, F. (1982). Energía e industrialización. En G. Gutman y D. Mezger (Eds.), ¿Nueva o vieja división internacional del trabajo? Industrialización en Venezuela y México (pp. 429-472). Instituto Latinoamericano de Investigaciones Sociales, ILDIS/ Centro de Estudios del Desarrollo, CENDES/ Editorial Ateneo de Caracas. 
Moldiz, H. (2020). Golpe de Estado en Bolivia. La soledad de Evo Morales. Ocean Sur.

Molina, F. (2019a). Bolivia: "es la economía estúpido". Nueva Sociedad, (283), 4-14.

Molina, F. (2019b). Bolivia. ¿Golpe o (contra)revolución? Nueva Sociedad. https://nuso.org/articulo/bolivia-golpe-o-contrarevolucion/

Molina, F. (2020). Los primeros pasos de Luis Arce en el laberinto boliviano. Nueva Sociedad. https://nuso.org/articulo/luis-arceEvo-Morales-Bolivia/

Montero, L. (2020). Estrategias discursivas de lo femenino en política: Una supermadre en el poder. En F. Mayorga (Coord.), Crisis y cambio político en Bolivia. Octubre y noviembre de 2019: la democracia en una encrucijada (pp. 163-191). Centro de Estudios Superiores Universitarios de la Universidad Mayor de San Simón (CESU-UMSS) / Comité de Oxford de Ayuda contra el Hambre (Oxford Committee for Famine Relief), Oxfam.

Montoya, J. (2019). Rol del Presidente Duque en la crisis de la democracia en Venezuela. En M. Barrios y M. Bisbal (Eds.), Búsqueda de alternativas políticas a la crisis de Venezuela. Seminario Internacional (pp. 121-125). Universidad Católica Andrés Bello.

Mora, J., Rojas, A., Fargier, M., Ramírez, V., Vargas, G., Tonella, G., y Domingo, C. (2017). Venezuela: Estado rentista, reparto y desigualdad 1999-2014. En C. Peña (Comp.), Venezuela y su tradición rentista: visiones, enfoques y evidencias (pp. 165-204). Consejo Latinoamericano de Ciencias Sociales, CLACSO/ Universidad Central de Venezuela/Instituto de Investigaciones Económicas y Sociales Dr. Rodolfo Quintero.

Morales, J. (1993). Política económica después de la transición a la democracia. En M. Pacheco (Comp.), Bolivia en la hora de su modernización (pp. 129-157). Universidad Nacional Autónoma de Mexica, UNAM.

Moreno, A. (1996). Neoliberalismo y conflictos sociales en Venezuela (1989-1993). En E. Figueroa (Ed.), Violencia y miseria en el crepúsculo del siglo (pp. 45-64). Benemérita Universidad Autónoma de Puebla, BUAP.

Mosonyi, E. (2009). Balance general de los diez años del proceso bolivariano: pueblos indígenas. Revista Venezolana 
de Economía y Ciencias Sociales, 15(1), 155-172. http:// ve.scielo.org/scielo.php?script=sci_abstract $\&$ pid=S1315$64112009000100008 \& \operatorname{lng}=\mathrm{en} \& \mathrm{nrm}=\mathrm{iso} \& \ln \mathrm{l}=\mathrm{es}$

Nava, A. ( julio de 2007). Hacia una recomprensión del tiempo histórico venezolano. VI Jornadas Nacionales de Investigación Humanística y Educativa. Universidad de Zulia.

Nava, A. (2009). La década de 1990 en una recomprensión del tiempo histórico venezolano contemporáneo. Ensayos Históricos. Anuario de Estudios Hispanoamericanos, 21(21), 143-171.

Oliveros, A. (2019). Del exceso de Hugo Chávez a la Venezuela pospetrolera de Nicolás Maduro. En M. Barrios y M. Bisbal (Eds.), Búsqueda de alternativas políticas a la crisis de Venezuela. Seminario Internacional (pp. 25-34). Universidad Católica Andrés Bello.

Ormachea, E. (1987). Beni y Pando. Latifundio y minifundio en el norte boliviano. Centro de Estudios para el Desarrollo Laboral y Agrario, CEDLA.

Pérez, N. (2014). Revolución Boliviana de 1952. Ocean sur.

Pérez, R. (1999). Réquiem para el fomento. Sobre la relación entre el Estado y negocios a través de la historia del Ministerio de Fomento. Politeia, (23), 141-162.

Petkoff, T. (2010). El chavismo como problema. Editorial Libros Marcados.

Petras, J. (2013). El capitalismo extractivo y las diferencias en el bando latinoamericano progresista. En J. Petras y J. Lora (Eds.), Extractivismo y simulacro progresista en Bolivia y Latinoamérica (pp. 9-22). Benemérita Universidad Autónoma de Puebla, BUAP/Instituto de Ciencias Sociales y Humanidades "Alfonso Vélez Pliego".

Pinto, M. (2005). Las élites y el pueblo, sus alianzas y sus divisiones. Estudio comparativo de las coaliciones democráticas en Bolivia (1952 y 1985). Análisis político, (54), 88-100. https://revistas.unal.edu.co/index.php/anpol/article/view/46644/48025

Plata, W. (2008). El discurso autonomista de las élites de Santa Cruz. En X. Soruco (Coord.), Los Barones del Oriente. El poder de Santa Cruz ayer y hoy (pp. 101-171). Fundación TIERRA.

Programa de las Naciones Unidas para el Desarrollo, PNUD (2004). Informe de desarrollo humano en Santa Cruz 2004. PNUD. 
Programa de las Naciones Unidas para el Desarrollo, PNUD (2007). Informe nacional sobre Desarrollo Humano, 2007. El estado del Estado en Bolivia. PNUD.

Programa de las Naciones Unidas para el Desarrollo, PNUD (2015). Informe nacional sobre desarrollo humano en Bolivia. El nuevo rostro de Bolivia. Transformación social y metropolización. PNUD.

Quintero, R. (1972). Antropología del petróleo. Siglo XXI editores.

Ramos, R. (1993). Problemas textuales y metodológicos de la sociología histórica. Revista Española de Investigaciones Sociológicas, (63), 7-28. https://doi.org/10.2307/40183647

Rey, J. (1991). La democracia venezolana y la crisis del sistema populista de conciliación de élites. Revista de Estudios Políticos (Nueva Época), (74), 533-578.

Rey, J. (2015). El sistema de partidos venezolano 1830-1999. Editorial Jurídica Venezolana.

Rivera, S. (1993). Democracia liberal y democracia de "ayllu". En M. Miranda (Comp.), Bolivia en la hora de su modernización (pp. 217-255). Universidad Nacional Autónoma de México, UNAM.

Rivera, S. (2010). Oprimidos pero no vencidos. Luchas del campesinado Aymara y Qhechwa 1900-1980. La mirada salvaje.

Rivera, S. (2014). Mito y desarrollo en Bolivia. El giro colonial del gobierno del MAS. Plural editores.

Rivero, Á. (2019). El papel de Estados Unidos en la actual crisis venezolana. En M. Barrios y M. Bisbal (Eds.), Búsqueda de alternativas políticas a la crisis de Venezuela. Seminario Internacional (pp. 93-119). Universidad Católica Andrés Bello.

Robinson, W. (2015). América Latina y el capitalismo global: una perspectiva crítica de la globalización. Siglo XXI editores.

Roca, J. (2005). Estatalidad: entre la pugna regional y el institucionalismo. En R. Barragán, y J. Roca (Eds.), Cuaderno del Futuro 21. Regiones y poder constituyente en Bolivia. Una historia de pactos y disputas (pp. 217-274). Programa de las Naciones Unidas para el Desarrollo, PNUD.

Roca, J. (2009). Regionalismo, fenómeno omnipresente en Bolivia. En J. Crabtree, G. Gray Molina, y L. Whitehead (Eds.), Tensiones Irresueltas. Bolivia, pasado y presente (pp. 69-90). Programa 
de las Naciones Unidas para el Desarrollo, PNUD/Plural editores.

Rodríguez, G. (2001). Los mineros de Bolivia en una perspectiva histórica. Convergencia. Revista de Ciencias Sociales, 8(24), 271198. https://convergencia.uaemex.mx/article/view/1790

Rodríguez, G. (2012). Las antinomias del nacionalismo revolucionario. Documento para el debate. En M. Zuazo, J. Faguet, y G. Bonifaz (Eds.), Descentralización y democratización en Bolivia. La historia del Estado débil, la sociedad rebelde y el anhelo de democracia (pp. 87-123). Friedrich Ebert Stiffung, FES.

Rodríguez, M. (2019). La crisis constitucional de Venezuela: algunos componentes de relevancia internacional. Revista Electrónica Iberoamericana, 13(2), 158-203. https://urjc.es/images/ceib/revista_electronica/vol_13_2019_2/REIB_13_02_19_Articulo6.pdf

Rojas, C. (2015). Conflictividad en Bolivia (2000-2014). ¿Cómo revertir la normalización de la presión social? Friedrich Ebert Stiffung, FES.

Rojas, G. (2009). Cultura política de las élites en Bolivia (1985-2002). Friedrich Ebert Stiffung, FES /Centro de Investigación y Promoción del Campesinado, CIPCA.

Rojas, G. (2018). Estado y democracia en Bolivia la hora crítica. Umbrales. Revista del Postgrado en Ciencias del Desarrollo, (34), 137-160. http://www.cides.edu.bo/webcides 2/index.php/ component/jdownloads/send/8-revista-umbrales/158-revista-umbrales-34

Romero, A. (2003). Crisis de la movilidad social. Crisis de legitimidad. En A. Romero, E. Sandoval, y R. Salazar (Coords.), Venezuela: horizonte democrático en el siglo XXI (pp. 31-45). Sociedad Zuliana de Sociología.

Romero, S. (2002). La elección presidencial 2002: una visión del conjunto. Opiniones y análisis, (57), 157-223.

Romero, S. (2003). CONDEPA y UCS: el declive del neopopulismo boliviano. Revista de Ciencia Política, (1), 67-98.

Romero, S. (2006). Estudio de la elección presidencial 2005. Opiniones y análisis, (77), 131-183.

Romero, S. (2012a). Sufragio universal y democracia en Bolivia: una perspectiva de medio siglo. En S. Gómez-Tagle y W. Sonleitner (Eds.), Mutaciones de la democracia: tres décadas de 
cambio político en América Latina (1980-2010). Colegio de México, COLMEX.

Romero, S. (2012b). El sistema de partidos en Bolivia 1952-2012. En M. Zuazo, J. Faguet, y G. Bonifaz (Eds.), Descentralización y democratización en Bolivia. La historia del Estado débil, la sociedad rebelde y el anhelo de democracia (pp. 125-185). Friedrich Ebert Stiffung, FES.

Ruiz, M. (2012). Crisis estatal y lucha de clases en la Venezuela contemporánea. Corporación Editora Nacional.

Sader, E. (2009). El nuevo topo: los caminos de la izquierda latinoamericana. Siglo XXI editores.

Santeliz, A. (2017). El petróleo en la economía venezolana. En C. Peña (Comp.), Venezuela y su tradición rentista: visiones, enfoques y evidencias (pp. 205-234). Consejo Latinoamericano de Ciencias Sociales, CLACSO/ Universidad Central de Venezuela/ Instituto de Investigaciones Económicas y Sociales Dr. Rodolfo Quintero.

Skocpol, T. (1984). Los Estados y las revoluciones sociales. Un análisis comparativo de Francia, Rusia y China. Fondo de Cultura Económica.

Soruco, X. (Coord.) (2008a). Los Barones del Oriente. El poder de Santa Cruz ayer y hoy. Fundación TIERRA.

Soruco, X. (2008b). De la goma a la soya: el proyecto histórico de la elite cruceña. En X. Soruco (Coord.), Los Barones del Oriente. El poder de Santa Cruz ayer y hoy (pp. 1-100). Fundación TIERRA.

Soto, C. (1994). Historia del pacto militar campesino. Centro de Estudios de la Realidad Económica y Social.

Stefanoni, P. (2019). ¿Qué pasa en Bolivia? Nueva Sociedad. https:// nuso.org/articulo/Bolivia-Evo-Morales-Carlos-Mesa-elecciones/

Stefanoni, P. y Molina, F. (2019). Bolivia y la contrarrevolución ¿Cómo derrocaron a Evo? Revista Anfibia. http://revistaanfibia. com/ensayo/como-derrocaron-a-evo/

Tapia, L. (2018). La democracia como fantasma histórico. Umbrales. Revista del Postgrado en Ciencias del Desarrollo, (34), 125136. http://www.cides.edu.bo/webcides2/index.php/component/jdownloads/send/8-revista-umbrales/158-revistaumbrales-34 
Tellería, L. (2004). Fuerzas Armadas, seguridad interna y democracia en Bolivia: entre la indefinición estratégica y la criminalización social. Informe Consejo Latinoamericano de Ciencias Sociales. Consejo Latinoamericano de Ciencias Sociales, CLACSO.

Tilly, C. (1992). Coerción, capital y los Estados europeos, 990-1990. Alianza Editorial.

Tilly, C. (2010). Democracia. Akal.

Toranzo, C. (1993). Burguesía "Chola" una sorpresa de la sociología boliviana. En M. Miranda (Comp.), Bolivia en la hora de su modernización (pp. 285-301). Universidad Nacional Autónoma de México, UNAM.

Torres, J. (2003). Crisis históricas y populismo: el paro cívico en Venezuela. En A. Romero, E. Sandoval, y R. Salazar (Coords.), Venezuela: horizonte democrático en el siglo XXI (pp. 252-314). Sociedad Zuliana de Sociología.

Torrez, V. (2018). Reelección indefinida y el horizonte de la democracia en Bolivia. Umbrales. Revista del Postgrado en Ciencias del Desarrollo, (34), 187-210. http://www.cides.edu.bo/webcides2/index.php/component/jdownloads/send/8-revistaumbrales/158-revista-umbrales-34

Torrico, M. (2017). Introducción. Giro a la izquierda en América Latina: las explicaciones teóricas y el desempeño de los gobiernos. En M. Torrico (Ed.), ¿Fin de giro a la izquierda en América Latina? Gobiernos y políticas públicas (pp. 9-34). Facultad Latinoamericana de Ciencias Sociales, FLACSO-México.

Uharte, L. (2013). La disputa política por la hegemonía democrática en Bolivia. Intersticios: Revista Sociológica de Pensamiento Crítico, 7(2), 149-166. https://www.intersticios.es/article/ view/11438/8235

Vera, L. (2018). ¿Cómo explicar la catástrofe económica venezolana? Nueva Sociedad, (274), 83-96. https://nuso.org/articulo/como-explicar-la-catastrofe-economica-venezolana/

Viaña, J. (2011). La compleja trama de permanente interlocución/ruptura entre los movimientos sociales y el gobierno del MAS en Bolivia 2006-2009. En R. Cortéz (Coord.), Cuadernos de Futuro 26. Claves de la transición del poder (pp. 19-94). Programa de las Naciones Unidas para el Desarrollo, PNUD. 
Vilera, A. (2003). Conciliación democrática en Venezuela. ¿Desde dónde? En A. Romero, E. Sandoval, y R. Salazar (Coords.), Venezuela: horizonte democrático en el siglo XXI (pp. 109-129). Sociedad Zuliana de Sociología.

Zambrano, L. (10-11 de marzo de 2015). El petróleo y la política macroeconómica en la Venezuela contemporánea. Academia Nacional de Ciencias Económicas, Instituto de Estudios Superiores de Administración. https://www.ucab.edu.ve/ wp-content/uploads/sites/2/2017/09/Petroleo-y-PoliticaMacroeconomica-Venezuela.pdf

Zuazo, M. (2009). ¿Cómo nació el MAS? La ruralización de la política en Bolivia. Entrevista a 85 parlamentarios del partido. Friedrich Ebert Stiffung, FES.

Zuazo, M. (2012). Bolivia, cuando el Estado llegó al campo. Municipalización, democratización y nueva Constitución. En M. Zuazo, F. Faguet, y G. Bonifaz (Eds.), Descentralización y democratización en Bolivia. La historia del Estado débil, la sociedad rebelde y el anhelo de democracia (pp. 187-286). Friedrich Ebert Stiffung, FES. 